\title{
Evaluation of the Effect of Platelet Rich Plasma on Wound Healing in the Tongue of Normal and Streptozotocin-induced Diabetic Albino Rats: Histological, Immunohistochemical, and Ultrastructural Study
}

\author{
Mary Moheb Ramzy ${ }^{1 *}$, Tarik Ahmed Essawy ${ }^{2}$, Ali Shamaa ${ }^{1}$, Saher Sayed Ali Mohammed ${ }^{1}$ \\ ${ }^{1}$ Department of Oral Biology, Faculty of Dentistry, Minia University, Minya, Egypt; ${ }^{2}$ Department of Oral Biology, Faculty of Oral \\ and Dental Medicine, Cairo University, Giza, Egypt
}

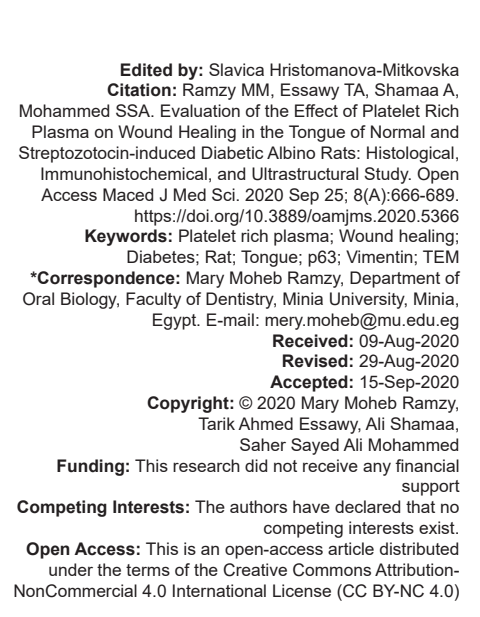

\section{Introduction}

Diabetes mellitus (DM) is one of the most common endocrine metabolic disorders in the world. World Health Organization (WHO) has recently declared it to be a pandemic. It is characterized by hyperglycemia due to a total or relative lack of insulin secretion and insulin resistance or both [1], [2].

Streptozotocin (STZ) is used to induce diabetes in experimental rats. The STZ-induced diabetes results in a diabetic status in experimental animals like that observed in diabetic patients [3], [4].

It has been well-documented that there is delayed or incomplete healing of wounds in diabetic humans and in animal models of diabetes. DM affects all phases of healing. It alters the function of cells from the monocyte-macrophage system which play key roles in inflammation and wound healing [5], [6], [7].

In humans and in all mammalian species, the wound healing process can be subdivided into four distinct consecutive and overlapping phases including hemostasis, inflammation, cellular and matrix proliferation, and remodeling. These phases are regulated by various cells, cytokines, and growth factors which can act directly over the responsible cells for their release, nearby cells or even distant cells [8], [9].

Identification of methods to enhance wound healing is a target of significant potential benefit. Wounds in high risk circumstances as DM would profit from accelerating wound healing [10].

The use of platelet-rich plasma (PRP) to enhance wound healing has increased dramatically over the last decade. PRP is defined as a portion of the plasma fraction of autologous blood with a platelet concentration above baseline [11], [12].

At present, the use of PRP has attracted great attention and has grown substantially spanning many fields of medicine including cardiovascular surgery, gastrointestinal medicine, orthopedics, sports medicine, dentistry, maxillofacial surgery, wound 
healing, dermatology, cosmetic surgery, plastic, and reconstructive surgery [13], [14], [15]

The main advantage of the therapeutic PRP use that makes it attractive for clinical use is that it can be prepared from the patient's own blood without complex equipment or staff training. Furthermore, because it is autologous, PRP does not provoke an immune response in the patient and is therefore perceived to have a high margin of therapeutic safety [14], [16].

The tongue of white laboratory rats is a welldeveloped muscular organ that has an elongated shape in the rostrocaudal direction with an extended tip. The mucous membrane covers the dorsal, ventral, and lateral surfaces of the tongue. The ventral surface of the apex of the rat tongue is covered by a thin keratin layer and small filiform papillae and a few fungiform papillae are localized on the ventral surface of the tongue around the edges of the apex, while the ventral surface of the body of the tongue is smooth without papillae [17], [18].

p63 is a marker of keratinocytes with a high proliferative potential and it was reported to be involved in the control of physiologic processes, such as cell proliferation and migration, related to epidermal repair during healing of normal skin in humans [19].

Vimentin is a structural protein belonging to the type III of intermediate filament proteins. It is a $57 \mathrm{kDa}$ intermediate filament protein, which forms a part of the cytoskeleton. It is expressed in cells of mesenchymal origin which include fibroblasts, endothelial cells, macrophages, melanocytes, Schwann cells, and lymphocytes. Vimentin is usually not expressed in epithelial cells [20], [21].

Transmission electron microscopes (TEMs) are capable of imaging at a significantly higher resolution than light microscopes. Therefore, TEM can be used to investigate tissues and the organization of organelles within large cells at nanometer scale resolution [22], [23].

Despite the multitude of clinical and basic science studies published within the last years, many important questions remain unanswered including those concerning the best dosing, timing, and frequency of PRP injections and optimal physiologic conditions for injections [24]. Moreover, whether PRP could be used as a prophylactic rather than a therapeutic especially in diabetic wounds; is also an unanswered issue.

Hence, our study was done to address some of these unanswered questions and to find a practical method to enhance early wound healing in oral mucosa in normal and diabetic tongue. Furthermore, limited studies evaluated the effect of PRP immunohistochemically and ultrastructurally on oral tissues, which makes the present study interesting.

\section{Materials and Methods}

Animals: A total number of 108 adult male albino rats (average weight $=200 \mathrm{~g}$ ) were used in this study. The animals were housed in cages at the Faculty of Medicine, Minia University in Egypt under the optimal experimental conditions. Animals were fed on ground barley and supplied water ad-libitum. Housing and environmental conditions were assured to meet the basic needs of the animal subjects. Ethical guidelines for use of animals in scientific research were carefully followed throughout this experiment in accordance to Tandon et al. [25] and to the recommendations and approval of the Ethics Committee on animal experimentation of the Faculty of Dentistry, Minia University in Egypt.

\section{Experimental design}

The animals were classified into two main groups:

The non-diabetic group (Group N): comprised 54 animals. They were injected with citrate buffer [26], [27]. These animals were subdivided into three subgroups (18 animals each):

- $\quad$ Subgroup N1: was the control group. The rats received an incisional wound in their tongues. These rats were in turn divided into three subgroups (six animals each):

Subgroup N1A: The rats were sacrificed on the $1^{\text {st }}$ day post-operative.

Subgroup N1B: The wounded tongue was injected with saline on post-operative day 1 , and then the rats were sacrificed on the $3^{\text {rd }}$ day post-operative.

- $\quad$ Subgroup N1C: The wounded tongue was injected with saline on post-operative days 1 and 3 , and then the rats were sacrificed on the $7^{\text {th }}$ day post-operative.

-

Subgroup N2: $0.1 \mathrm{ml}$ of freshly prepared PRP was injected in the rats' tongues 10 min before the incisional wound. These rats were in turn divided into three subgroups (six animals each): Subgroup N2A: The rats were sacrificed on the $1^{\text {st }}$ day post-operative.

Subgroup N2B: The wounded tongue was injected with saline on post-operative day 1 , and then the rats were sacrificed on the $3^{\text {rd }}$ day post-operative.

- $\quad$ Subgroup N2C: The wounded tongue was injected with saline on post-operative days 1 and 3 , and then the rats were sacrificed on the $7^{\text {th }}$ day post-operative.

Subgroup N3: The rats' tongues were injected with $0.1 \mathrm{ml}$ of freshly prepared PRP after the incisional wound. These rats were in turn divided into three subgroups (six animals each): 
- $\quad$ Subgroup N3A: PRP was injected into the wounded tongue on post-operative day 0 and the rats were sacrificed on the $1^{\text {st }}$ day post-operative.

- $\quad$ Subgroup N3B: PRP was injected into the wounded tongue on post-operative days 0 and 1 , and then the rats were sacrificed on the $3^{\text {rd }}$ day post-operative.

Subgroup N3C: PRP was injected into the wounded tongue on post-operative days 0 , 1 , and 3 , and then the rats were sacrificed on the $7^{\text {th }}$ day post-operative.

The diabetic group (Group D): comprised 54 animals. Diabetes was induced in these rats by a single intraperitoneal injection of $45 \mathrm{mg} / \mathrm{kg}$ body weight of streptozotocin (STZ) (Sigma, St. Louis, MO, USA) dissolved in $0.1 \mathrm{M}$ citrate buffer $(\mathrm{pH} 4.5)$ [5]. This group in turn was subdivided into three subgroups (18 animals each):

Subgroup D1: The rats received an incisional wound in their tongues after induction of diabetes. These rats were further divided into three subgroups (six animals each): D1A, $\mathrm{D} 1 \mathrm{~B}$, and D1C and the wounded tongue were injected with saline like the control subgroups $\mathrm{N} 1 \mathrm{~A}, \mathrm{~N} 1 \mathrm{~B}$, and N1C, respectively.

- $\quad$ Subgroup D2: The diabetic rats were treated with PRP before the incisional wound. These rats were further divided into three subgroups (six animals each): D2A, D2B, and D2C and the wounded tongue were injected with saline like subgroups $\mathrm{N} 2 \mathrm{~A}, \mathrm{~N} 2 \mathrm{~B}$, and $\mathrm{N} 2 \mathrm{C}$, respectively.

Subgroup D3: The diabetic rats were treated with PRP after the incisional wound. These rats were further divided into three subgroups (six animals each): D3A, D3B, and D3C. PRP was injected into the wounded tongue on postoperative days such as subgroups N3A, N3B, and $\mathrm{N} 3 \mathrm{C}$, respectively.

\section{Induction of diabetes}

After $48 \mathrm{~h}$, the blood glucose level was determined among rats that received STZ injection. Blood samples were collected through the tail vein and the glucose level was estimated using glucometer. Rats with persistent blood glucose levels $\geq 250 \mathrm{mg} / \mathrm{dL}$ until wounding were confirmed diabetic and used for the experiment [26].

\section{Wounding procedure}

General anesthesia was induced in all the animals using intramuscular injection of ketamine at a dose of $20 \mathrm{mg} / \mathrm{kg}$. Then, the incisional wound was made on the lateral border of the rat tongue $1 \mathrm{~cm}$ length and $0.5 \mathrm{~cm}$ depth using a small surgical scalpel. These measurements were marked on the blade of the scalpel to insure that all the wounds were of the same length and depth in all the groups [10].

\section{Preparation of PRP}

Whole blood was drawn from each rat that was going to be treated with PRP, from the retroorbital plexus using capillary tube, under general anesthesia. The blood was then centrifuged at 6000 $\mathrm{rpm}$ (revolutions $/ \mathrm{min}$ ) for $3 \mathrm{~min}$ at room temperature. This resulted in separation of blood into three fractions which are red blood cells (bottom layer), platelet-poor plasma (PPP) (top layer), and PRP (middle layer, including white blood cells and platelets [buffy coat]). PRP was then aspirated with a pipette and placed in a sterile syringe to be ready for injection [28].

PRP treatment: The injection into the tongue tissue was done using a $1 \mathrm{~mL}$ insulin syringe with a needle size 27 gauge $\times 1 / 2$ inch. The injection was 2-3 mm deep and was done slowly to allow proper diffusion of PRP solution in the tongue tissue [29].

\section{Histological Procedures}

On termination of the experiment, the animals were humanely sacrificed under general anesthesia on post-operative days 1,3 , and 7 . The animals were anaesthetized by diethyl ether $\left[\left(\mathrm{C}_{2} \mathrm{H}\right)_{2} \mathrm{O}\right]$ inhalation.

Specimens from the normal and diabetic rats' tongues were carefully dissected perpendicular to the wound sites and to the midline of their tongues. Half of these specimens were fixed in $10 \%$ neutral buffered formalin for histological and immunohistochemical analysis; the other half of the specimens were fixed in glutaraldehyde for $24-48 \mathrm{~h}$ at $4^{\circ} \mathrm{C}$ for transmission electron microscopic analysis.

\section{Light microscopic preparation}

The tongue samples fixed in formalin were washed under running tap water, then dehydrated through ascending grades of ethyl alcohol, cleared in $x y l o l$, and embedded in paraffin wax. Sections of $5 \mu$ thick were cut, mounted on clean glass slides, and stained with routine H\&E stain to verify histological details. All these methods were adopted according to Drury and Wallington [30]. Additional sections were prepared for p63 and vimentin immunohistochemical staining.

\section{technique \\ p63 immunohistochemical staining}

Formalin-fixed, paraffin-embedded tissue blocks were cut and picked up onto positively charged slides. 
The sections were then deparaffinized and rehydrated. Antibodies against p63 (Dako, Denmark, M7247, 1:60) were then applied to the slides. The p63 antigen was retrieved in $1 \mathrm{mM}$ EDTA buffer, $\mathrm{pH} 8$, by heating in a pressure cooker on high temperature for $15 \mathrm{~min}$. The primary antibody was diluted 1:60 and incubated for 30 min with the sections. Primary antibody and all subsequent incubations were $10 \mathrm{~min}$ each. Horseradish peroxidase conjugated to the final reagent was used to develop the brown diaminobenzidine (DAB) chromagen [31].

\section{technique}

Vimentin immunohistochemical staining

Immunostaining with mouse monoclonal vimentin antibody (Dako, Denmark, M0725, 1:200) was performed on the formalin-fixed, paraffin-embedded tissue blocks; for 30 min at room temperature. After rinsing in phosphate-buffered saline, the sections were incubated with biotinylated secondary antibody. Detection was performed with diaminobenzidine (DAB) and counter-stained with Mayer hematoxylin followed by dehydration and mounting [32].

\section{Microscopic examination of the histological slides}

The prepared slides (H\&E, MT, p63, and VIM) were examined and photographed using light microscope (LEICA, model DM LB100T, Germany) connected to digital camera (LEICA Microsystem, Type DFC295, Germany) in Histopathology Unit in Faculty of Dentistry, Minia University.

\section{Immunohistochemical analysis}

Immunohistochemically stained sections (both p63 and VIM) were examined using Image $J 22$ software in Histopathology Unit in Faculty of Dentistry, Minia University. p63 and VIM immunostaining was measured as area fraction in a standard measuring frame in six fields in each group using magnification $(\times 200)$ by light microscopy transferred to the screen. The areas showing p63 positive (+ve) and VIM +ve brown immunostaining were chosen for evaluation, regardless the intensity of staining. These areas were masked by a red binary color to be measured by the computer system.

\section{Statistical analysis}

Data entry and analysis were made using Statistical Package for the Social Sciences (SPSS) software version 22.0 for Windows. Graphics were also done using SPSS. Quantitative data related to the area fraction of p63 and VIM immunoreactivity were presented as mean and standard deviation values. Analysis of variance (ANOVA) test was used to detect statistical significance of the difference between all groups. The probability of $<0.05$ was used as a cutoff point for all results.

\section{Method of TEM processing}

Four blocks $(1 \times 2 \mathrm{~mm})$ were taken from each sample and fixed in $5 \%$ cold glutaraldehyde immediately after dissecting the animals for 24-48 $\mathrm{h}$. The specimens were then washed in cacodylate buffer $(\mathrm{pH} \mathrm{7.2)} \mathrm{3-4}$ times for 20 min every time and post fixed in $1 \%$ osmium tetroxide $\left(\mathrm{O}_{4} \mathrm{~S}_{4}\right)$ for $2 \mathrm{~h}$, after that washed in the same buffer 4 times. Dehydration by ascending grades of alcohol (30-50-70-90 and 100\% $2 \mathrm{~h}$ ) of each was done. Specimens were then embedded in epon - araldite mixture [33]. From the embedded blocks, semithin sections by LKB ultramicrotome in thickness of $0.5-1$ micron were prepared for orientation of the tissue. These semithin sections were photographed by SC30 Olympus camera. Ultrathin sections in thickness of 500-700A were made using Leica AG ultramicrotome and contrasted in uranyl acetate and lead citrate. Ultrathin sections were examined by JEM 100 CXII electron microscope at $80 \mathrm{KV}$ and photographed by CCD digital camera Model XR-41 at the Electron Microscopy Unit of Assiut University.

\section{Results}

Before starting the main procedures of the experiment, seven rats died after the induction of diabetes and so they were replaced. Two STZ-induced diabetic rats died during the experiment and were also replaced.

I-Hematoxylin and Eosin Stain Results

First: The non-diabetic group (Group N):

Subgroup N1: On the $1^{\text {st }}$ day post-operative, a break in the continuity of the covering epithelium where the incision was made was revealed in subgroup N1A. The open wound was observed with non-keratinized margins. There was a wide gap separating the lamina propria from the underlying muscle layer. On the $3^{\text {rd }}$ day post-operative in subgroup N1B, the wound gap appeared to be filled with non-keratinized epithelium composed of undifferentiated keratinocytes. The granulation tissue was composed mainly of fibroblasts and newly formed blood vessels. On the $7^{\text {th }}$ day post-operative in subgroup N1C, the wound gap appeared to be healed with stratified squamous epithelium covered by thin layer of keratin. Lamina propria showed congested blood vessels and perivascular edema (Figure 1).

- $\quad$ Subgroup N2: On the $1^{\text {st }}$ day post-operative in subgroup N2A, keratinized stratified squamous epithelium with edematous keratinocytes partly covering the wound site (on one margin) due to 
sectioning was revealed. The epithelium was found to cover granulation tissue composed of fibroblasts and newly formed blood vessels. On the $3^{\text {rd }}$ day post-operative in subgroup $\mathrm{N} 2 \mathrm{~B}$, complete healing by formation of lightly stained keratinized stratified squamous epithelium was displayed. Thin layer of lamina propria with absence of granulation tissue was shown. Newly formed non-congested blood vessels were clearly seen. On the $7^{\text {th }}$ day postoperative in subgroup $\mathrm{N} 2 \mathrm{C}$, complete healing by formation of deeply stained keratinized stratified squamous epithelium with welldifferentiated keratinocytes was revealed. Thin layer of lamina propria appeared with newly formed blood vessels (Figure 1).

- $\quad$ Subgroup N3: On the $1^{\text {st }}$ day post-operative in subgroup N3A, inflamed keratinized stratified squamous epithelium partly covering the wound area (on one margin) due to sectioning was displayed. Granulation tissue appeared with inflammatory cell infiltrate and congested blood vessels. On the $3^{\text {rd }}$ day post-operative in subgroup N3B, the wound area started to heal by formation of thick layer of edematous stratified squamous epithelium. Keratinocytes appeared to be undifferentiated and there was absence of rete pegs. Granulation tissue with inflammatory cell infiltrate and newly formed blood vessels was seen. On the $7^{\text {th }}$ day post-operative in subgroup N3C, complete healing with formation of thick layer of keratinized stratified squamous epithelium took place. Obvious granular cell layer with abundant keratohyalin granules was shown. Thin layer of lamina propria with newly formed blood vessels was displayed (Figure 1).

Second: The diabetic group (Group D):

Subgroup D1: On the $1^{\text {st }}$ day post-operative in subgroup D1A, a break in the continuity of the covering epithelium where the incision was made was revealed. The wound gap appeared to be encompassed by non-keratinized epithelial margins. Hemorrhage was noticed in the wound space. On the $3^{\text {rd }}$ day post-operative in subgroup D1B, granulation tissue was clearly noticed filling the wound gap and containing inflammatory cell infiltrate. Wound margins appeared to be composed of keratinized stratified squamous epithelium. Extensive inflammatory cell infiltrate was apparent in the lamina propria. On the $7^{\text {th }}$ day post-operative in subgroup D1C, partial healing in the wound epithelial covering was noticed with presence of small wound gap. The keratinized stratified squamous epithelium appeared lightly stained. Thin lamina propria was present (Figure 1).

- $\quad$ Subgroup D2: On the $1^{\text {st }}$ day post-operative in subgroup D2A, thin layer of keratinized stratified squamous epithelium partly covering the wound site (on one margin) due to sectioning was displayed. Thin lamina propria with newly formed blood vessels was displayed. On the $3^{\text {rd }}$ day post-operative in subgroup $\mathrm{D} 2 \mathrm{~B}$, the wound appeared to be completely healed with thick layer of keratinized stratified squamous epithelium with edematous keratinocytes. Lamina propria presented extensive C.T. composed mainly of fibroblasts and inflammatory cell infiltrate together with newly formed blood vessels. On the $7^{\text {th }}$ day post-operative in subgroup D2C, the wound was observed to be completely healed with keratinized stratified squamous epithelium with edematous keratinocytes and regular rete pegs. Lamina propria appeared thin with deeply stained fibroblasts (Figure 1).

Subgroup D3: On the $1^{\text {st }}$ day post-operative in subgroup D3A, a break in the continuity of the covering epithelium where the incision was made was revealed. The wound margins were found to be covered by a thin layer of keratinized stratified squamous epithelium. Hemorrhage was noticed in the wound space and lamina propria showed widely dilated and congested blood vessels. On the $3^{\text {rd }}$ day postoperative in subgroup D3B, the wound gap was noticed to be surrounded by edematous keratinized stratified squamous epithelial margins. Granulation tissue appeared to invade lamina propria with inflammatory cell infiltrate, fibroblasts, and newly formed blood vessels. On the $7^{\text {th }}$ day post-operative in subgroup D3C, the wound area was found to be completely healed by thin, lightly stained layer of keratinized stratified squamous epithelium with regular rete pegs. Lamina propria showed thick collagen bundles (Figure 1).

II-p63 Immunohistochemical Stain Results

First: The non-diabetic group (Group N):

- $\quad$ Subgroup N1: All control subgroups revealed moderate $\mathrm{p} 63$ positive nuclear immune reaction only in the basal cell layer of the epithelium, whether in the wound margins or in the healed epithelium. All cells in the lamina propria or granulation tissue presented negative p63 nuclear immune reaction (Figure 2).

- Subgroup N2: Subgroup N2A revealed moderate p63 positive nuclear immune reaction in the basal, suprabasal, and spinous cell layers of the epithelium of the wound margins. Meanwhile, subgroup N2B revealed intense p63 positive nuclear immune reaction in the basal and suprabasal cell layers of the healed epithelium. As for subgroup N2C, it showed moderate p63 positive nuclear immune reaction in the basal and suprabasal cell layers of the healed epithelium (Figure 2). 


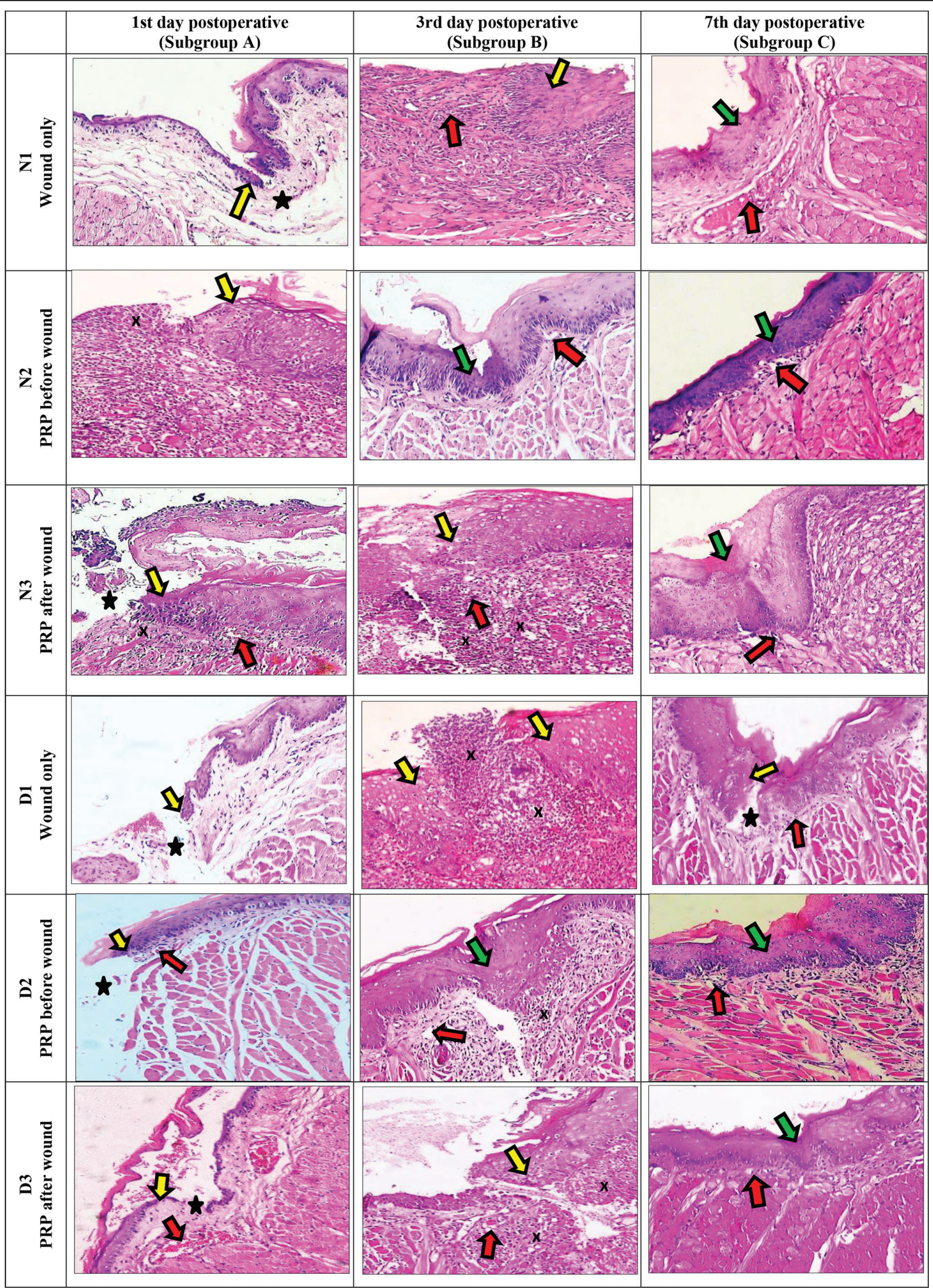

Figure 1: Photomicrographs of the wound area of the tongue of Non-diabetic subgroups (N1A, N1B, N1C, N2A, N2B, N2C, N3A, N3B, and N3C) and Diabetic subgroups (D1A, D1B, D1C, D2A, D2B, D2C, D3A, D3B, and D3C) showing wound margins (yellow arrow), wound gap (star), blood capillaries in lamina propria (red arrow), granulation tissue with inflammatory cell infiltrate (x), and completely healed epithelium with keratinized stratified squamous epithelium (green arrow). (H\&E X200)

- $\quad$ Subgroup N3: Subgroup N3A displayed intense p63 positive nuclear immune reaction in the basal and suprabasal cell layers, as well as in some focal areas in the spinous cell layer of 


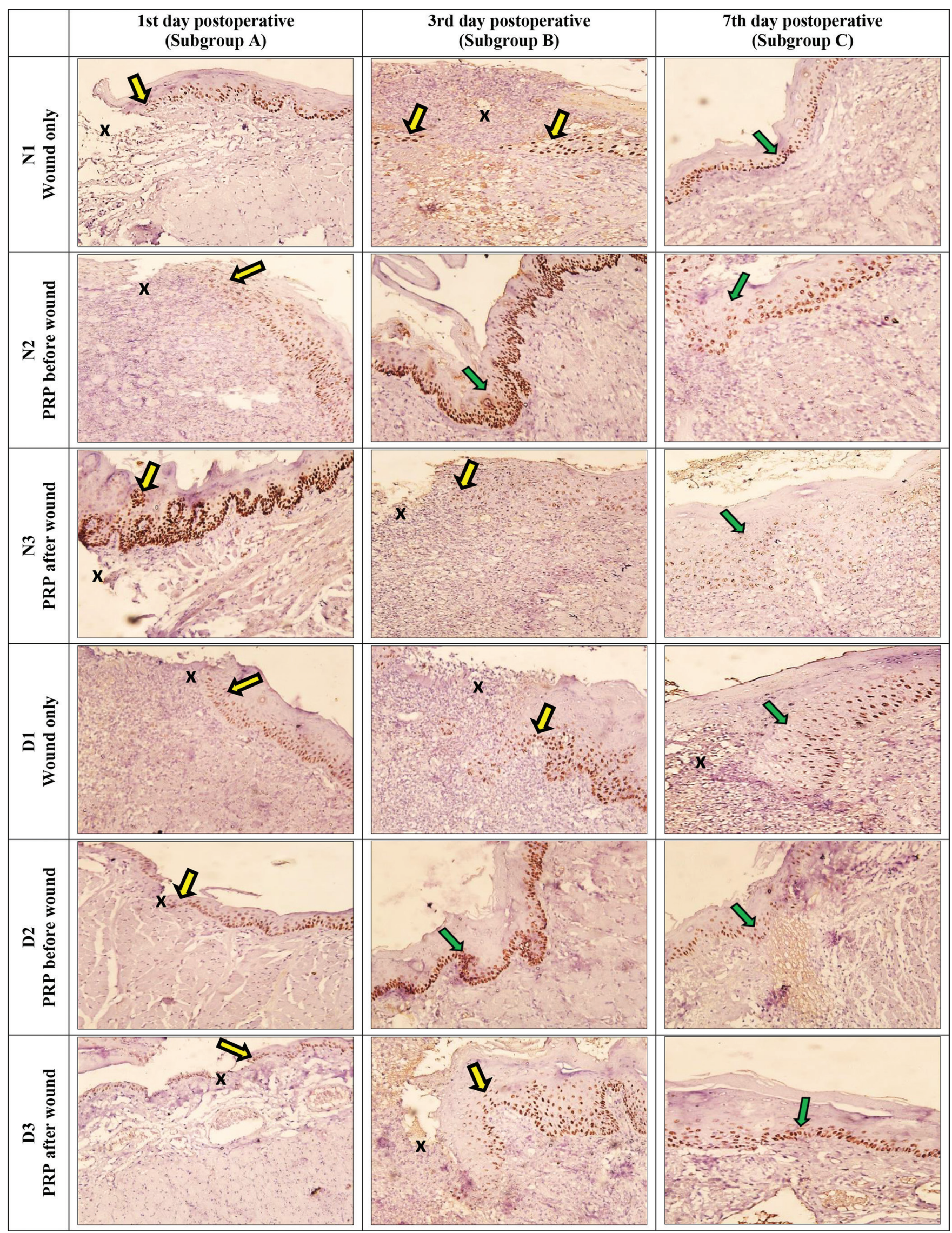

Figure 2: Photomicrographs of the wound area of the tongue of Non-diabetic subgroups (N1A, N1B, N1C, N2A, N2B, N2C, N3A, N3B, and $N 3 C)$ and diabetic subgroups (D1A, D1B, D1C, D2A, D2B, D2C, D3A, D3B, and D3C) showing wound gap (x), p63 positive nuclear immune reaction in the wound margins (yellow arrow), and healed epithelium (green arrow), ranging between weak, moderate or intense immune reactions; and ranging in distribution between basal cell layer only; basal and suprabasal cell layers; or basal, suprabasal, and spinous cell layers of the epithelium. (p63 X200) 
the epithelium of the wound margins. On the other hand, subgroup N3B revealed weak p63 positive nuclear immune reaction in the basal, suprabasal, and spinous cell layers of the epithelium of the wound margin. As for subgroup $\mathrm{N} 3 \mathrm{C}$, it showed weak p63 positive nuclear immune reaction in the basal and suprabasal cell layers of the healed epithelium (Figure 2).

Second: The Diabetic group (Group D):

Subgroup D1: Subgroups D1A and D1B showed moderate $\mathrm{p} 63$ positive nuclear immune reaction in the basal and suprabasal cell layers of the epithelium of the wound margins. As for subgroup D1C, it showed moderate p63 positive nuclear immune reaction in the basal and suprabasal cell layers of the partially healed epithelium (Figure 2).

Subgroup D2: Moderate p63 positive nuclear immune reaction in the basal cell layer of the epithelium of the wound margins was revealed in subgroup D2A. However, subgroup D2B revealed intense p63 positive nuclear immune reaction in the basal cell layer of the healed epithelium. Moreover, subgroup D2C displayed moderate p63 positive nuclear immune reaction in the basal cell layer of the healed epithelium (Figure 2).

- $\quad$ Subgroup D3: Subgroup D3A revealed moderate p63 positive nuclear immune reaction in the basal cell layer of the epithelium of the wound margins. On the other hand, the nuclear immune reaction in subgroup D3B was also moderately p63 positive but this time it was displayed in both the basal and suprabasal cell layers of the epithelium of the wound margins. The immune reactions in subgroup $\mathrm{D} 3 \mathrm{C}$ appeared to be moderately p63 positive in the basal cell layer of the healed epithelium (Figure 2).

\section{Statistical analysis of $p 63$ results}

When comparing mean p63 area fraction between non-diabetic subgroups N1A, N1B, and N1C, the mean difference was insignificant $(p=0.43)$. While the mean difference between subgroups N2A, N2B, and $\mathrm{N} 2 \mathrm{C}$ was highly significant $(p=0.001)$. Moreover, the mean difference between subgroups N3A, N3B, and N3C was also highly significant $(p=0.001)$ (Table 1$)$ and (Figure 3).

When comparing mean p63 area fraction between diabetic subgroups D1A, D1B, and D1C, the mean difference was insignificant $(p=0.44)$. While the mean difference between subgroups D2A, D2B, and D2C was highly significant $(p=0.001)$. Moreover, the mean difference between subgroups D3A, D3B, and D3C was also highly significant $(p=0.001)$ (Table 2) and (Figure 4).

Comparison between all the non-diabetic and diabetic subgroups during the $1^{\text {st }}$ day post-operative, the
Table 1: Mean p63 area fraction among different subgroups in the non-diabetic category

\begin{tabular}{|c|c|c|c|c|}
\hline & \multicolumn{4}{|c|}{ Mean p63 area fraction among non-diabetic group (N) } \\
\hline & $\begin{array}{l}\text { 1st day post- } \\
\text { operative (A) }\end{array}$ & $\begin{array}{l}\text { 3rd day post- } \\
\text { operative (B) }\end{array}$ & $\begin{array}{l}\text { 7th day post- } \\
\text { operative (C) }\end{array}$ & $P$ value \\
\hline Wound only (N1) & $3.05 \pm 1.1$ & $3.75 \pm 1.03$ & $3.83 \pm 1.2$ & $\begin{array}{l}F=0.90 \\
P=0.43\end{array}$ \\
\hline PRP before wound (N2) & $6.81 \pm 0.77$ & $12.34 \pm 1.8$ & $6.22 \pm 0.64$ & $\begin{array}{l}F=49.54 \\
P=0.001^{*}\end{array}$ \\
\hline PRP after wound (N3) & $13.20 \pm 2.7$ & $8.37 \pm 1.3$ & $7.26 \pm 0.99$ & $\begin{array}{l}F=17.57 \\
P=0.001^{*}\end{array}$ \\
\hline
\end{tabular}

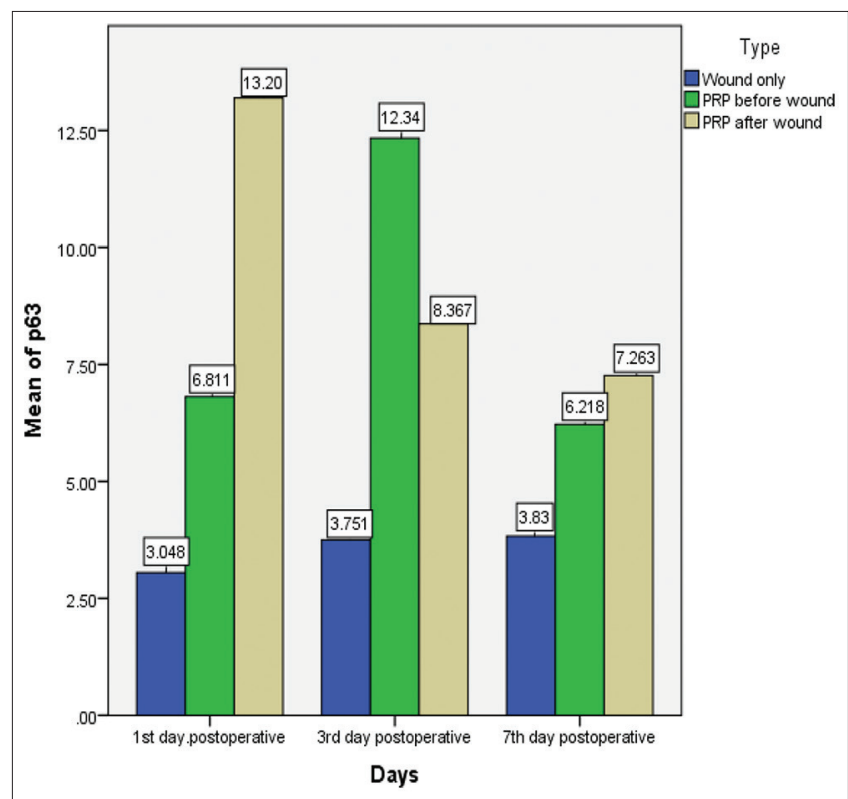

Figure 3: Comparison of mean values of $p 63$ area fraction among the different subgroups in the Non-diabetic group $(N)$

$3^{\text {rd }}$ day post-operative, and the $7^{\text {th }}$ day post-operative was exhibited in Tables 3-5, respectively.

III-Vimentin (VIM) Immunohistochemical Stain Results

First: The non-diabetic group (Group N):

Subgroup N1: Subgroup N1A revealed moderate VIM positive nuclear immune reaction of fibroblasts and endothelial cells of newly formed blood vessels in the lamina propria. Subgroup N1B displayed intense VIM positive nuclear immune reaction. The granulation tissue filling the wound gap also showed intense VIM positive nuclear immune reaction of inflammatory cells. Meanwhile, subgroup N1C revealed moderate VIM positive nuclear immune reaction. The epithelium showed negative nuclear immune reaction for VIM (Figure 5).

Table 2: Mean p63 area fraction among different subgroups in the diabetic category

\begin{tabular}{|c|c|c|c|c|}
\hline & \multicolumn{4}{|c|}{ Mean p63 area fraction among diabetic group (D) } \\
\hline & $\begin{array}{l}1^{\text {st }} \text { day } \\
\text { post-operative }(\mathrm{A})\end{array}$ & $\begin{array}{l}3^{\text {rd }} \text { day post- } \\
\text { operative (B) }\end{array}$ & $\begin{array}{l}7^{\text {th }} \text { day post- } \\
\text { operative }(C)\end{array}$ & $p$ value \\
\hline Wound only (D1) & $5.78 \pm 2.4$ & $7.19 \pm 3.2$ & $7.53 \pm 1.3$ & $\begin{array}{l}F=0.86 \\
p=0.44\end{array}$ \\
\hline PRP before wound (D2) & $5.98 \pm 1.7$ & $11.74 \pm 2.8$ & $6.83 \pm 1.3$ & $\begin{array}{l}F=14.50 \\
p=0.001^{*}\end{array}$ \\
\hline PRP after wound (D3) & $3.67 \pm 0.80$ & $8.54 \pm 2.58$ & $7.13 \pm 0.91$ & $\begin{array}{l}f=13.90 \\
p=0.001^{*}\end{array}$ \\
\hline
\end{tabular}




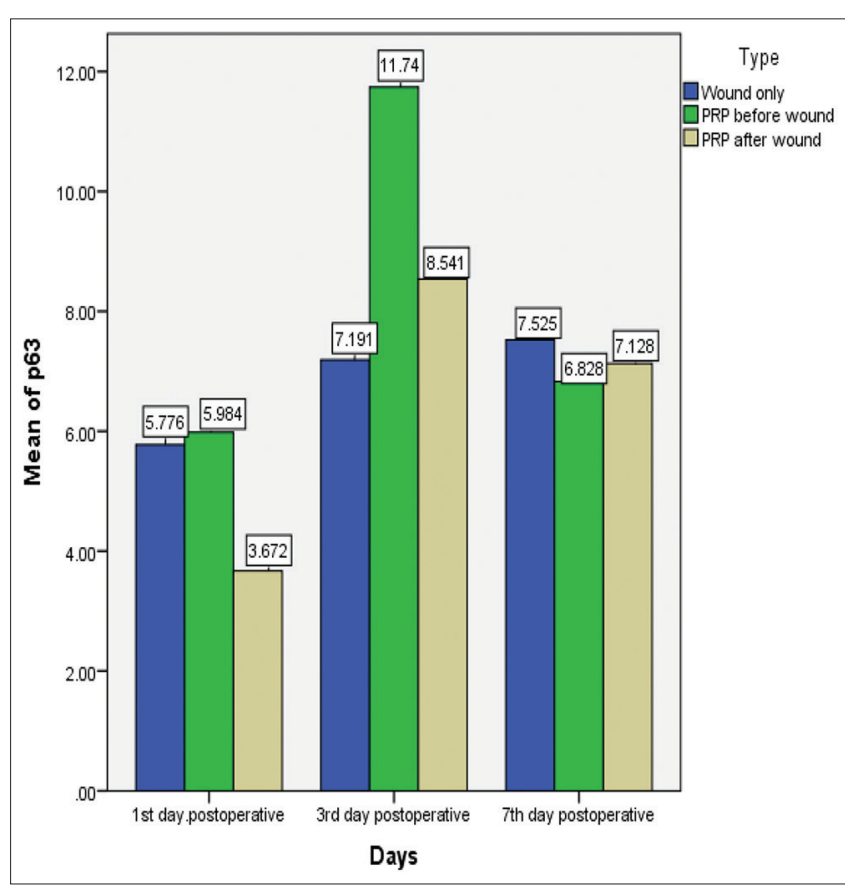

Figure 4: Comparison of mean values of $p 63$ area fraction among the different subgroups in the Diabetic group (D)

Subgroup N2: Intense VIM positive immune reaction of fibroblasts and endothelial cells of newly formed blood vessels in the lamina

Table 3: Mean p63 area fraction among different subgroups in the $1^{\text {st }}$ day post-operative

\begin{tabular}{llll}
\hline & \multicolumn{3}{l}{$\begin{array}{l}\text { Mean p63 area fraction among } 1^{\text {st }} \text { day post-operative } \\
\text { subgroups (A) }\end{array}$} \\
\cline { 2 - 4 } & Non-diabetic (N) & Diabetic (D) & P value \\
\hline Wound only (1) & $3.05 \pm 1.1$ & $5.78 \pm 2.4$ & $\begin{array}{l}f=6.26 \\
p=0.03^{*} \\
f=1.24\end{array}$ \\
PRP before wound (2) & $6.81 \pm 0.77$ & $5.98 \pm 1.65$ & $\begin{array}{l}p=0.29 \\
f=67.13\end{array}$ \\
PRP after wound (3) & $13.20 \pm 2.7$ & $3.67 \pm 0.80$ & $p=0.001^{*}$ \\
P value & $F=51.34$ & $F=3.16$ & \\
\hline ANOVA test was used to compare means. The mean difference is significant at $p \leq 0.05\left(^{*}\right)$.
\end{tabular}

propria was obvious in subgroup N2A. The granulation tissue filling the wound gap also exhibited intense VIM positive nuclear immune reaction of inflammatory cells and fibroblasts. On the other hand, in subgroup N2B and $\mathrm{N} 2 \mathrm{C}$, the immune reactions of fibroblasts and endothelial cells of newly formed blood vessels in the lamina propria were found to be moderately positive for VIM. The newly formed blood vessels were most numerous in subgroup N2C (Figure 5).

Table 4: Mean p63 area fraction among different subgroups in the 3rd day post-operative

\begin{tabular}{|c|c|c|c|}
\hline & \multicolumn{3}{|c|}{$\begin{array}{l}\text { Mean p63 area fraction among } 3^{\text {rd }} \text { day post-operative } \\
\text { subgroups (B) }\end{array}$} \\
\hline & Non-diabetic $(\mathrm{N})$ & Diabetic (D) & $p$ value \\
\hline Wound only (1) & $3.75 \pm 1.03$ & $7.19 \pm 3.2$ & $F=6.26$ \\
\hline & & & $p=0.04^{*}$ \\
\hline PRP before wound (2) & $12.34 \pm 1.8$ & $11.74 \pm 2.8$ & $F=0.20$ \\
\hline PRP after wound (3) & $8.37 \pm 1.3$ & $8.54 \pm 2.6$ & $\begin{array}{l}p=0.67 \\
f=0.02\end{array}$ \\
\hline$P$ value & $\begin{array}{l}F=55.87 \\
p=0.001^{*}\end{array}$ & $\begin{array}{l}F=4.02 \\
p=0.04^{*}\end{array}$ & $p-0.09$ \\
\hline
\end{tabular}

Subgroup N3: Subgroup N3A displayed moderate VIM positive immune reaction of fibroblasts and endothelial cells of newly formed blood vessels in the lamina propria. However, subgroup N3B revealed intense VIM positive immune reaction. The granulation tissue filling the wound gap exhibited intense VIM positive nuclear immune reaction of inflammatory cells and fibroblasts. As for subgroup N3C, it showed moderate VIM positive immune reaction of fibroblasts and endothelial cells of newly formed blood vessels in the lamina propria. The epithelium of subgroups N3B and $\mathrm{N} 3 \mathrm{C}$ showed negative nuclear immune reaction for VIM, except for some scattered cells which appeared to be positive for VIM. (Figure 5).

Table 5: Mean p63 area fraction among different subgroups in the $7^{\text {th }}$ day post-operative

\begin{tabular}{|c|c|c|c|}
\hline & \multicolumn{3}{|c|}{$\begin{array}{l}\text { Mean p63 area fraction among } 7^{\text {th }} \text { day post-operative } \\
\text { subgroups (C) }\end{array}$} \\
\hline & Non-diabetic (N) & Diabetic (D) & $p$ value \\
\hline Wound only (1) & $3.83 \pm 1.2$ & $7.53 \pm 1.3$ & $\begin{array}{l}f=24.93 \\
p=0.001^{*}\end{array}$ \\
\hline PRP before wound (2) & $6.22 \pm 0.64$ & $6.83 \pm 1.3$ & $\begin{array}{l}f=1.05 \\
p=0.33\end{array}$ \\
\hline PRP after wound (3) & $7.26 \pm 0.99$ & $7.13 \pm 0.91$ & $\begin{array}{l}f=0.06 \\
p=0.81\end{array}$ \\
\hline$P$ value & $\begin{array}{l}F=19.3 \\
p=0.001^{*}\end{array}$ & $\begin{array}{l}F=0.51 \\
p=0.61\end{array}$ & \\
\hline
\end{tabular}

Second: The diabetic group (Group D):

- Subgroup D1: Subgroup D1A and D1B exhibited intense VIM positive immune reaction of fibroblasts and endothelial cells of newly formed blood vessels in the lamina propria. The granulation tissue filling the wound gap also revealed intense VIM positive nuclear immune reaction of inflammatory cells and fibroblasts. Moreover, subgroup D1C displayed moderate VIM positive immune reaction of fibroblasts, inflammatory cells, and endothelial cells of newly formed blood vessels in the lamina propria (Figure 5).

Subgroup D2: Subgroup D2A displayed intense VIM positive immune reaction of fibroblasts and endothelial cells of newly formed blood vessels in the lamina propria. Regarding subgroup $\mathrm{D} 2 \mathrm{~B}$ and $\mathrm{D} 2 \mathrm{C}$, they exhibited intense VIM positive nuclear immune reaction of inflammatory cells and fibroblasts present in the granulation tissue. Endothelial cells of newly formed blood vessels and fibroblasts in the lamina propria appeared to be with intense VIM positive nuclear immune reaction. The healed epithelium in both subgroups revealed negative nuclear immune reaction for VIM with the presence of some non-keratinocytes showing positive nuclear immune reaction for VIM (Figure 5).

- $\quad$ Subgroup D3: Moderate VIM positive immune reaction of fibroblasts and endothelial cells 


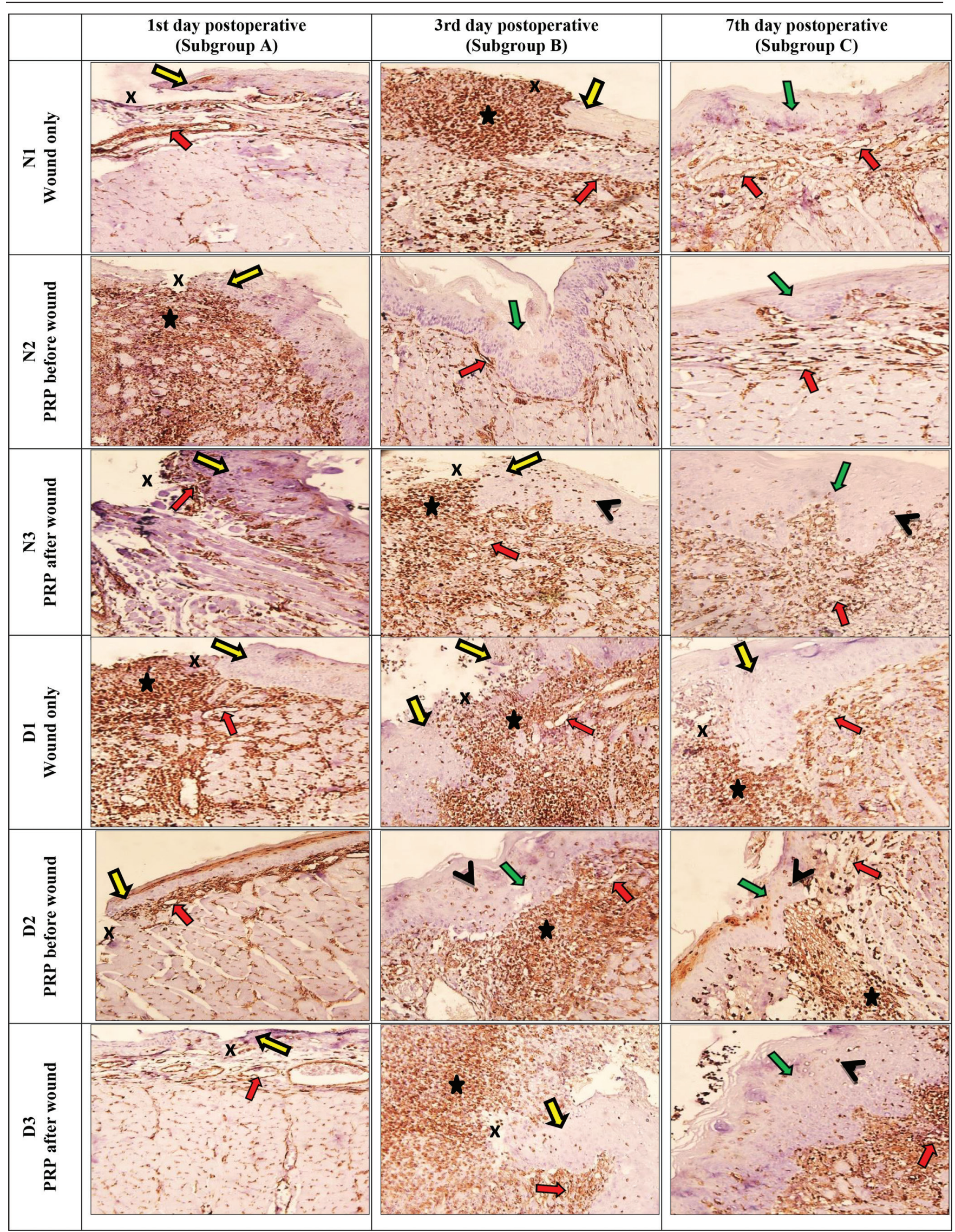

Figure 5: Photomicrographs of the wound area of the tonque of Non-diabetic subgroups (N1A, N1B, N1C, N2A, N2B, N2C, N3A, N3B, and $N 3 C$ ) and diabetic subgroups (D1A, D1B, D1C, D2A, D2B, D2C, D3A, D3B, and D3C) showing wound gap (x); granulation tissue with intense VIM +ve nuclear immune reaction of inflammatory cells (star); VIM +ve nuclear immune reaction of fibroblasts and endothelial cells of newly formed blood vessels (red arrows) in the lamina propria ranging between moderate and intense immune reactions; +ve VIM nuclear immune reaction in the wound margins (yellow arrow), and in healed epithelium (green arrow); and some non-keratinocytes showing +ve VIM nuclear immune reaction (black arrowhead). (VIM X200) 
of numerous newly formed blood vessels in the lamina propria was obvious in subgroup D3A. The blood vessels were noticed to be dilated. Meanwhile, in the subgroup D3B, the granulation tissue occupying the wound gap was found to exhibit intense VIM positive nuclear immune reaction of inflammatory cells and fibroblasts. The lamina propria contained fibroblasts and endothelial cells of newly formed blood vessels which showed intense positive nuclear immune reaction for VIM. As for subgroup $\mathrm{D} 3 \mathrm{C}$, the immune reaction of fibroblasts, inflammatory cells, and endothelial cells of newly formed blood vessels in the lamina propria was intensely positive for VIM. The healed epithelium revealed the presence of some non-keratinocytes displaying positive nuclear immune reaction for VIM (Figure 5).

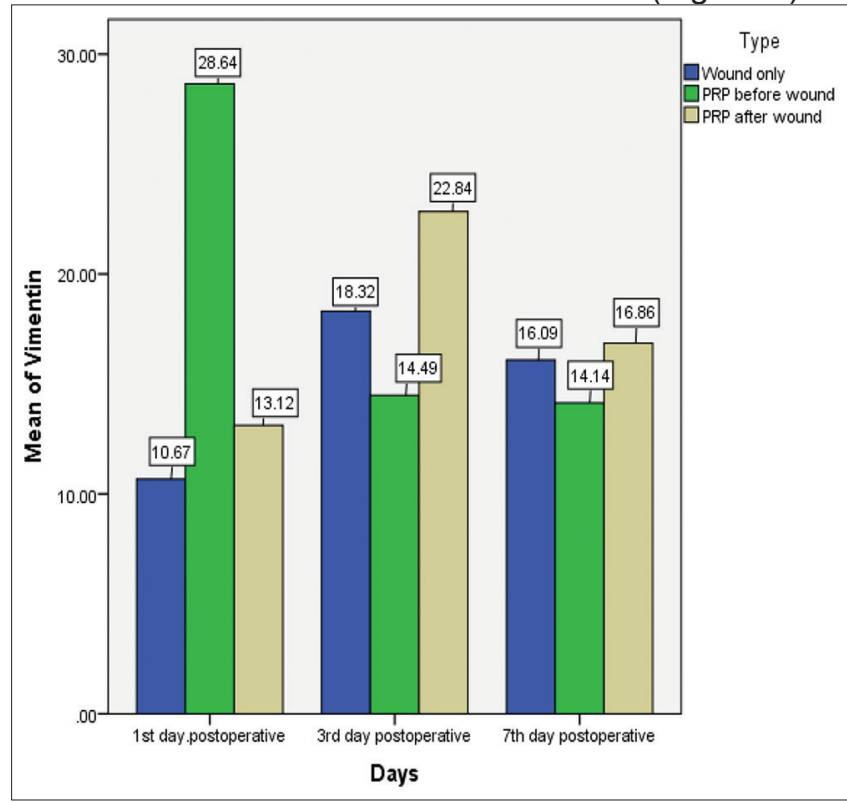

Figure 6: Comparison of mean values of VIM area fraction among the different subgroups in the Non-diabetic group (N)

\section{Statistical analysis of VIM results}

When comparing mean VIM area fraction between non-diabetic subgroups N1A, N1B and N1C, the mean difference was highly significant $(p=0.003)$. Moreover, the mean difference between subgroups $\mathrm{N} 2 \mathrm{~A}, \mathrm{~N} 2 \mathrm{~B}$, and N2C was also highly significant $(p=0.001)$. The mean difference between subgroups N3A, N3B, and N3C was likewise highly significant $(p=0.001)$ (Table 6) and (Figure 6).

Table 6: Mean VIM area fraction among different subgroups in the non-diabetic category

\begin{tabular}{|c|c|c|c|c|}
\hline & \multicolumn{4}{|c|}{ Mean VIM area fraction among non-diabetic group (N) } \\
\hline & $\begin{array}{l}1^{\text {st }} \text { day } \\
\text { post-operative (A) }\end{array}$ & $\begin{array}{l}3^{\text {rd }} \text { day post- } \\
\text { operative }(B)\end{array}$ & $\begin{array}{l}7^{\text {th }} \text { day } \\
\text { post-operative (C) }\end{array}$ & $p$ value \\
\hline Wound only (N1) & $10.67 \pm 3.3$ & $18.32 \pm 4.3$ & $16.09 \pm 1.3$ & $\begin{array}{l}F=9.1 \\
p=0.003^{*}\end{array}$ \\
\hline $\begin{array}{l}\text { PRP before } \\
\text { wound (N2) }\end{array}$ & $28.64 \pm 5.8$ & $14.49 \pm 1.7$ & $14.14 \pm 1.6$ & $\begin{array}{l}F=31.11 \\
p=0.001^{*}\end{array}$ \\
\hline $\begin{array}{l}\text { PRP after wound } \\
\text { (N3) }\end{array}$ & $13.12 \pm 2.9$ & $22.84 \pm 4.3$ & $16.86 \pm 2.1$ & $\begin{array}{l}F=13.8 \\
p=0.001^{*}\end{array}$ \\
\hline
\end{tabular}

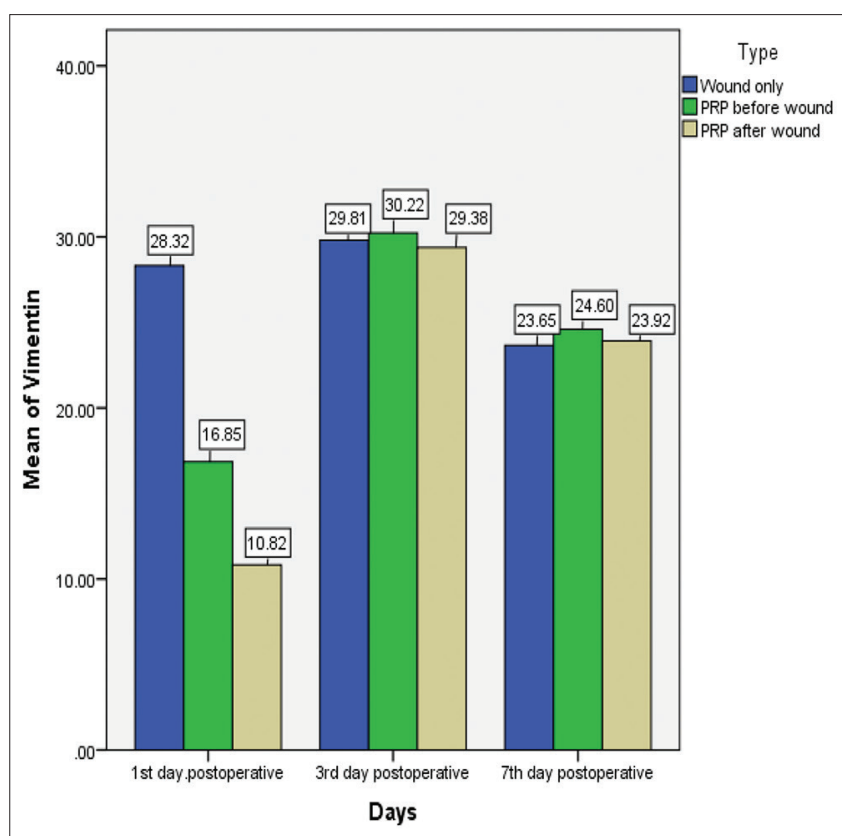

Figure 7: Comparison of mean values of VIM area fraction among the different subgroups in the Diabetic group (D)

When comparing mean VIM area fraction between diabetic subgroups D1A, D1B, and D1C, the mean difference was significant $(p=0.02)$. In addition, the mean difference between subgroups D2A, D2B, and $D 2 C$ was highly significant $(p=0.001)$. The mean difference between subgroups D3A, D3B, and D3C was also highly significant $(p=0.001)$ (Table 7$)$ and (Figure 7).

Table 7: Mean VIM area fraction among different subgroups in the diabetic category

\begin{tabular}{|c|c|c|c|c|}
\hline & \multicolumn{4}{|c|}{ Mean VIM area fraction among diabetic group (D) } \\
\hline & $\begin{array}{l}1^{\text {st }} \text { day post- } \\
\text { operative }(A)\end{array}$ & $\begin{array}{l}3^{\text {rd }} \text { day post- } \\
\text { operative }(B)\end{array}$ & $\begin{array}{l}7^{\text {th }} \text { day post- } \\
\text { operative (C) }\end{array}$ & $p$ value \\
\hline Wound only (D1) & $28.32 \pm 4.7$ & $29.81 \pm 3.5$ & $23.65 \pm 1.9$ & $F=4.91$ \\
\hline PRP before wound (D2) & $16.85 \pm 2.7$ & $30.22 \pm 2.5$ & $24.60 \pm 1.9$ & $\begin{array}{l}p=0.02^{*} \\
F=47.6\end{array}$ \\
\hline PRP after wound (D3) & $10.82 \pm 3.1$ & $29.38 \pm 5.7$ & $23.92 \pm 2.5$ & $\begin{array}{l}p=0.001^{*} \\
F=34.4 \\
p=0.001^{*}\end{array}$ \\
\hline
\end{tabular}

Comparison between all the non-diabetic and diabetic subgroups during the $1^{\text {st }}$ day post-operative, the $3^{\text {rd }}$ day post-operative, and the $7^{\text {th }}$ day post-operative was exhibited in Tables 8-10, respectively.

\section{IV- Transmission Electron Microscope Results}

First: The non-diabetic group (Group N):

- Subgroup N1: Ultra-thin sections of the wound area of the tongue of subgroup N1A and N1B, under TEM, displayed polyhedral cells having light electron dens cytoplasm and large indented vesicular nucleus containing two nucleoli. The basal cell layer appeared with presence of desmosomes and wide intercellular spaces in between the cells. Examination of subgroup N1C, under TEM, displayed the basal cell layer in the healing area showing indentation of the nucleus and 
vacuolation of the cell with condensation of the nuclear chromatin. The cytoplasm of the cells was rich in free ribosomes. The subepithelial C.T. was formed of well-developed collagenous C.T. containing collagen bundles, fibrocytes, and blood capillaries (Figure 8).

Table 8: Mean VIM area fraction among different subgroups in the $1^{\text {st }}$ day post-operative

\begin{tabular}{|c|c|c|c|}
\hline & \multicolumn{3}{|c|}{ Mean VIM area fraction among $1^{\text {st }}$ day post-operative subgroups $(A)$} \\
\hline & Non-diabetic $(\mathrm{N})$ & Diabetic (D) & $\mathrm{P}$ value \\
\hline Wound only (1) & $10.67 \pm 3.3$ & $28.32 \pm 4.7$ & $\mathrm{~F}=57.4$ \\
\hline & & & $p=0.001^{*}$ \\
\hline PRP before wound & $28.64 \pm 5.8$ & $16.85 \pm 2.7$ & $F=20.11$ \\
\hline (2) & & & $p=0.001^{*}$ \\
\hline $\begin{array}{l}\text { PRP after wound } \\
\text { (3) }\end{array}$ & $13.12 \pm 2.9$ & $10.82 \pm 3.1$ & $\begin{array}{l}F=1.7 \\
p=0.22\end{array}$ \\
\hline $\mathrm{P}$ value & $\begin{array}{l}F=31.9 \\
p=0.001^{*}\end{array}$ & $\begin{array}{l}F=36.85 \\
p=0.001^{*}\end{array}$ & \\
\hline
\end{tabular}

ANOVA test was used to compare means. The mean difference is significant at $p \leq 0.05\left({ }^{*}\right)$.

- Subgroup N2: Ultra-thin sections of subgroup N2A, under TEM, displayed elongated basal cells having indented vesicular nucleus, containing nucleolus and their cytoplasm was rich in free ribosomes, in addition to presence of some cells containing two nuclei. Subgroup N2B, under TEM, displayed the basal cell layer as elongated or cuboidal cells having large vesicular indented nucleus, some of which were in state of mitosis, and presence of wide intercellular spaces with desmosomes. Neutrophil cells containing a lobulated nucleus and lysosomal granules, as well as presence of macrophages, fibroblasts, collagen fibers, and red blood cells were observed in the lamina propria. Under TEM, subgroup N2C revealed large epithelial cells having large indented vesicular nucleus containing prominent nucleolus, and their cytoplasm rich in cell organelles especially free ribosomes. Meanwhile, the surface epithelial cells contained in their cytoplasm electron dens spherical hyaline granules which were variable in size, and their nucleus was light electron dens and indented (Figure 9).

Table 9: Mean VIM area fraction among different subgroups in the $3^{\text {rd }}$ day post-operative

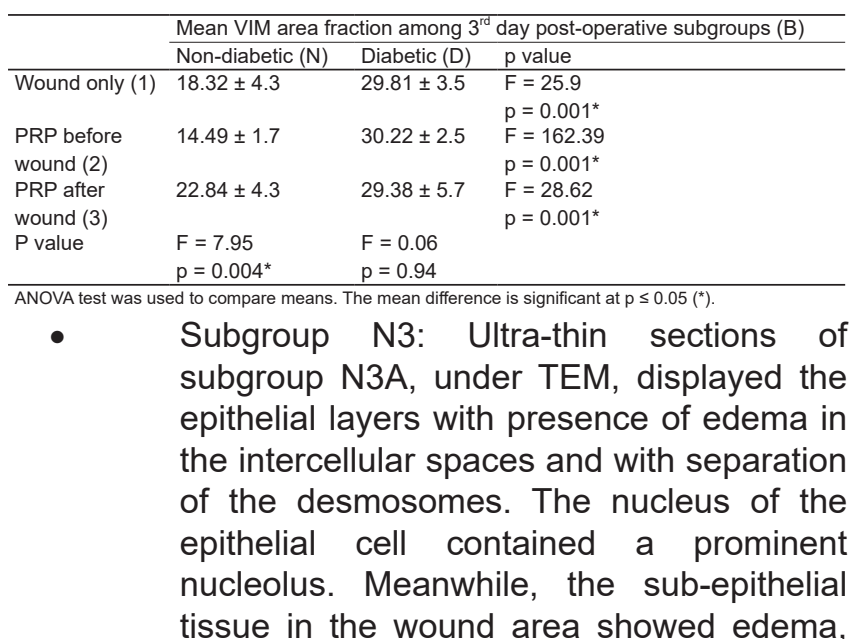

neutrophil, and macrophage cell infiltration, as well as presence of blood vessels. Ultrathin sections of subgroup N3B, under TEM, displayed the basal cells arranged in one cell line or multicellular layers of epithelial cells each having a nucleus variable in size and electron density and their cytoplasm was vacuolated. Subgroup N3C, under TEM, displayed the basal cells having large vesicular nucleus, some of which contained two nuclei and the cytoplasm was rich in free ribosomes. The surface epithelial cells were arranged in lamellar manner and their nucleus contained a nucleolus with presence of perinuclear space and their cytoplasm contained small electron dens hyaline granules (Figure 10).

Table 10: Mean VIM area fraction among different subgroups in the $7^{\text {th }}$ day post-operative

\begin{tabular}{llll}
\hline & \multicolumn{3}{l}{ Mean VIM area fraction among $7^{\text {th }}$ day post-operative subgroups $(\mathrm{C})$} \\
\cline { 2 - 4 } & Non-diabetic $(\mathrm{N})$ & Diabetic $(\mathrm{D})$ & $\mathrm{p}$ value \\
\hline Wound only (1) & $16.09 \pm 1.3$ & $23.65 \pm 1.9$ & $\mathrm{~F}=67.97$ \\
& & $\mathrm{p}=0.001^{*}$ \\
PRP before & $14.14 \pm 1.6$ & $24.60 \pm 1.9$ & $\mathrm{~F}=109.18$ \\
wound (2) & & & $\mathrm{p}=0.001^{*}$ \\
$\begin{array}{l}\text { PRP after } \\
\text { wound (3) }\end{array}$ & $16.86 \pm 2.1$ & $23.92 \pm 2.5$ & $\mathrm{~F}=28.62$ \\
P value & $\mathrm{F}=4.25$ & $\mathrm{~F}=0.32$ & $\mathrm{p}=0.001^{*}$ \\
& $\mathrm{p}=0.04^{*}$ & $\mathrm{p}=0.73$ & \\
\hline ANOVA test was used to compare means. The mean difference is significant at $\mathrm{p} \leq 0.05\left(^{*}\right)$.
\end{tabular}

Second: The diabetic group (Group D):

- Subgroup D1: Ultra-thin sections of subgroup D1A, under TEM, displayed elongated basal cells with large vesicular hyper-chromatic indented nucleus. Moreover, numerous layers of proliferating epithelial cells variable in size having large vesicular nucleus, vacuolated cytoplasm, wide intercellular spaces, and desmosomes were displayed in the upper epithelial layers. The sub-epithelial tissue was formed of fibrocytes, collagen fibers, myelinated nerve fibers, and macrophage cells containing electron dens lysosomes. Ultra-thin sections of subgroup D1B, under TEM, showed marked degenerative changes of the epithelial cells with presence of fat globules in their cytoplasm. Moreover, the sub-epithelial area of the wound displayed the presence of electron dens bacterial organisms, fungal organisms, macrophages, tissue debris, and edema. Subgroup D1C, under TEM, displayed elongated basal cells having large vesicular indented nucleus containing one or two prominent nucleoli and their cytoplasm was rich in free ribosomes, with the presence of numerous intercellular vacuoles (Figure 11).

- Subgroup D2: Ultra-thin sections of subgroup D2A, under TEM, displayed the basal cells having large vesicular nucleus 


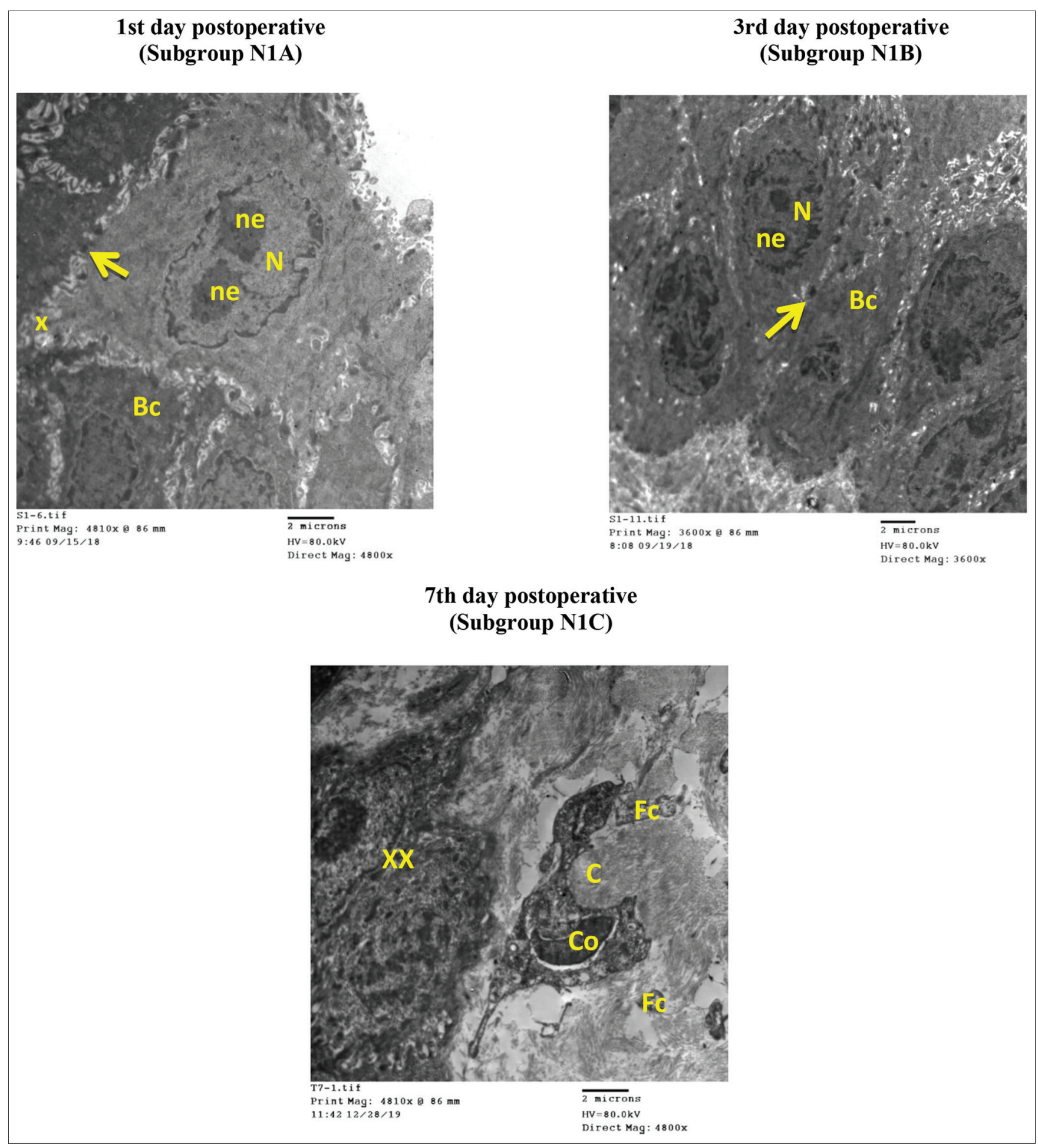

Figure 8: T.E. micrograph of the wound margin of subgroup N1A and N1B showing polyhedral cell with light electron dens cytoplasm, large indented vesicular nucleus $(N)$, two nucleoli (ne), and basal cells $(B c)$ with desmosomes (arrow) and wide intercellular spaces (X); the regenerated wound area of subgroup N1C showing the regenerated epithelial mucosa $(X X)$ and collagen bundles (Co), fibrocytes ( $F C)$ and blood capillaries (C) in the lamina propria

which contained large nucleolus and their cytoplasm contained mitochondria and free ribosomes, with presence of intercellular spaces and connections. The lamina propria in the wound area contained macrophages, neutrophils with lobulated nucleus, mast cells, collagen fibers, edema, blood capillaries, and myelinated nerve fibers. Ultra-thin sections of subgroup D2B displayed the basal cells with large vesicular indented nucleus containing nucleolus and their cytoplasm was rich in free ribosomes. The presence of some cells with two nuclei was also noticed. Subgroup D2C, under TEM, displayed the basal cells with large 


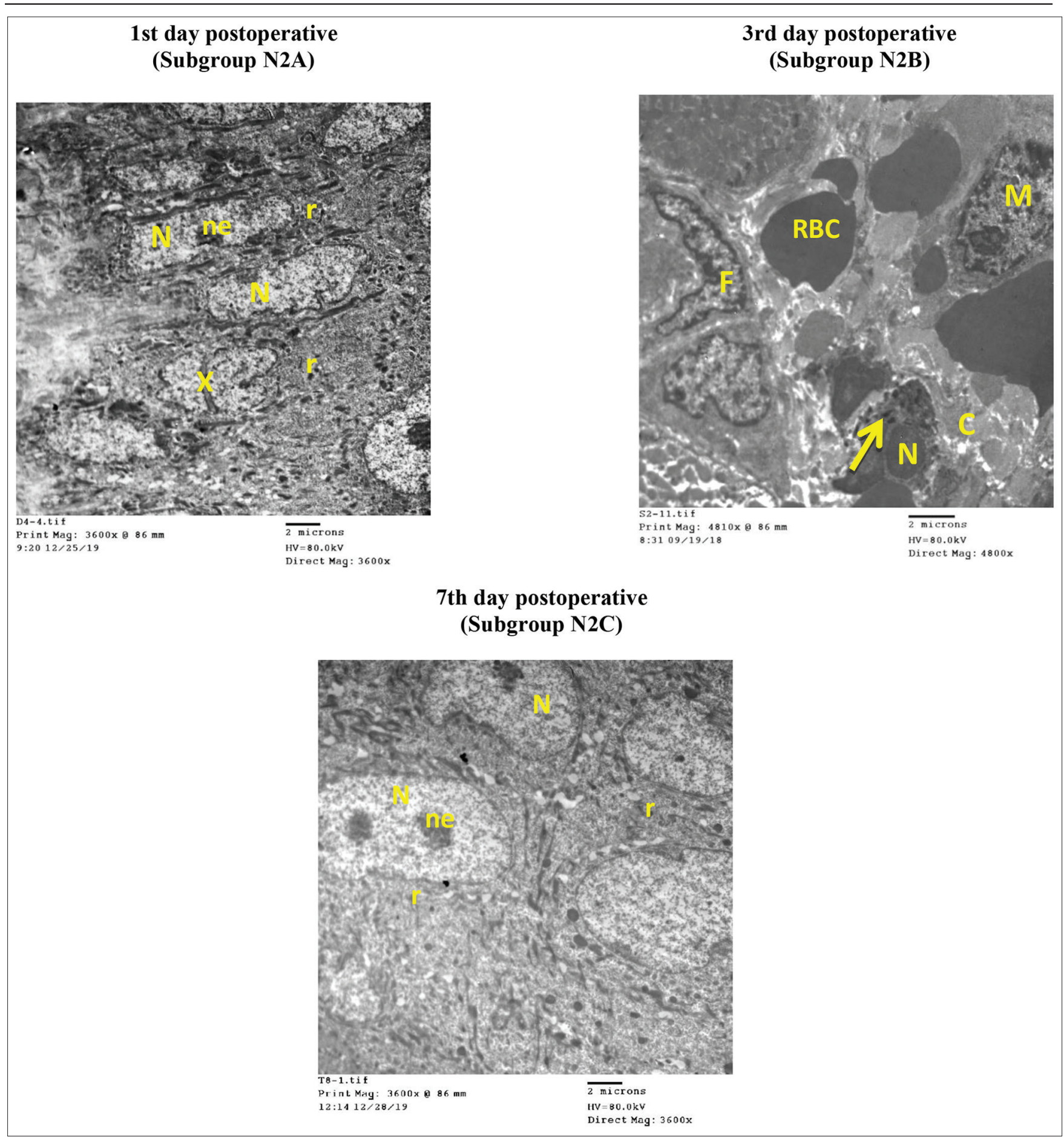

Figure 9: T.E. micrograph of the covering epithelium of the wound area of subgroup N2A showing elongated basal cells with indented vesicular nucleus ( $N$ ), nucleolus (ne), cytoplasm rich in free ribosomes (r), and cells with two nuclei $(X)$; the sub-epithelial tissue of wound healing area of subgroup N2B showing neutrophil cell (Nc) with lobulated nucleus and lysosomal granules (arrow), macrophages (Mc), fibroblasts $(F C)$, collagen fibers (Co) and red blood cells (RBC); the regenerated covering epithelium of the wound area of subgroup N2C showing large epithelial cells with large indented vesicular nucleus $(N)$, prominent nucleolus (ne), and cytoplasm rich in free ribosomes ( $r$ )

indented vesicular nucleus containing prominent nucleolus. The superficial cells had indented nucleus and their cytoplasm contained large amount of variable sized homogenous electron dens hyaline granules (Figure 12).

- Subgroup D3: Ultra-thin sections of subgroup D3A, under TEM, displayed cells with large indented nucleus and small amount of cytoplasm. The intercellular junctions were present in some areas and absent in other areas especially near the basal layer with wideness of the intercellular spaces. Subgroup D3B, under TEM, displayed marked degenerative changes of vacuolar type in the epithelial covering with 


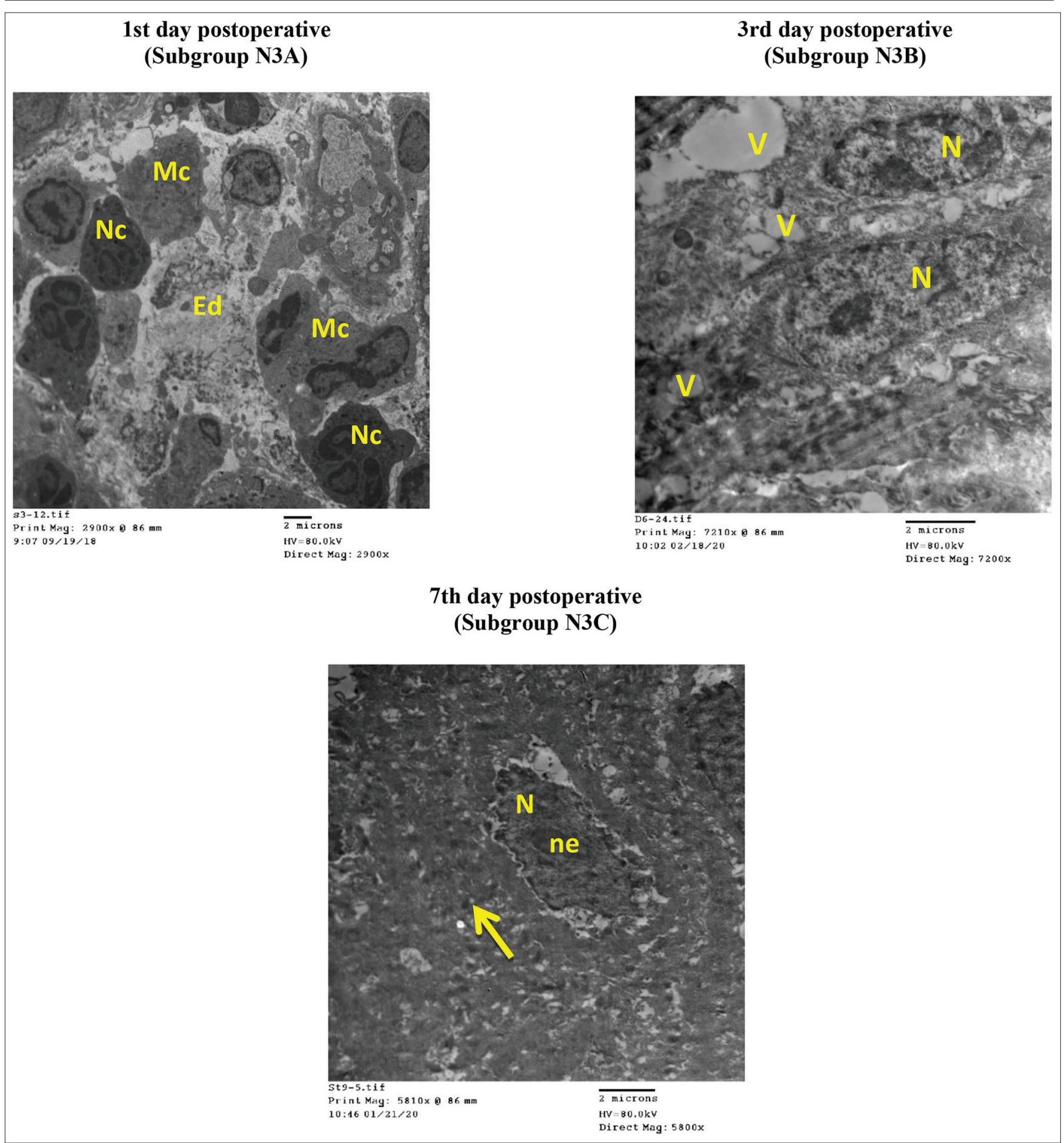

Figure 10: T.E. micrograph of the sub-epithelial tissue in the wound area of subgroup N3A showing edema (Ed), neutrophil (Nc) and macrophage cell (Mc) infiltration; the wound margin of subgroup N3B showing the basal cells arranged in one cell line or multicellular layers with nucleus $(\mathrm{N})$ variable in size and electron density and vacuolated cytoplasm $(\mathrm{V})$; the regenerated wound area of subgroup N3C showing the surface epithelial cells arranged in lamellar manner, nucleus $(N)$ with nucleolus (ne), and cytoplasm with small electron dens hyaline granules (arrow)

presence of fat globules. Moreover, large amount of macrophage cells containing large amount of electron dens particles either tissue debris or bacterial organisms were observed. Under TEM, subgroup D3C showed elongated basal cells containing indented vesicular nucleus and their cytoplasm was rich in free ribosomes and contained numerous vacuoles (Figure 13).

\section{Discussion}

Oral mucosa has the primary function of protecting the underlying tissues and limiting entry of microorganisms and toxins. Interruption in the continuity of the oral mucosa compromises this function. Therefore, an effective system of wound healing is required to restore the structure and function of the tissue after damage [9]. 


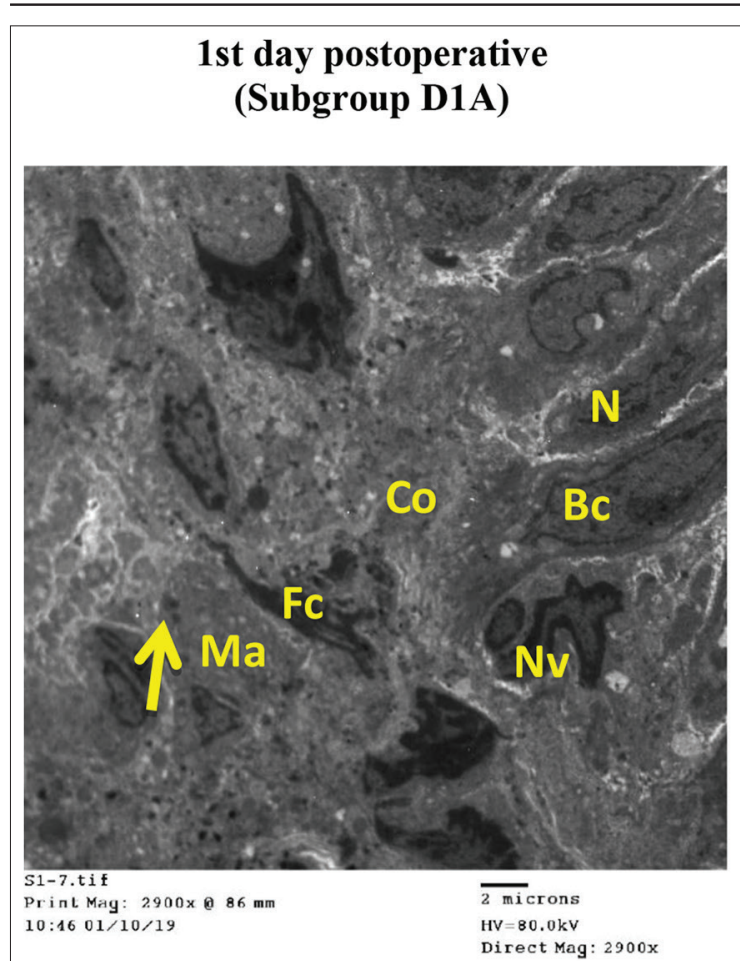

\section{3rd day postoperative (Subgroup D1B)}

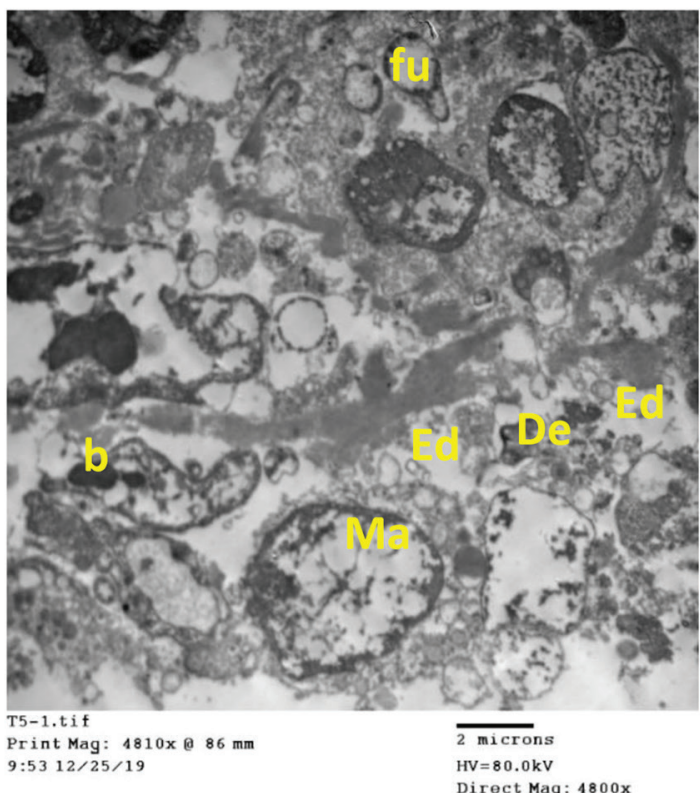

\section{7th day postoperative (Subgroup D1C)}

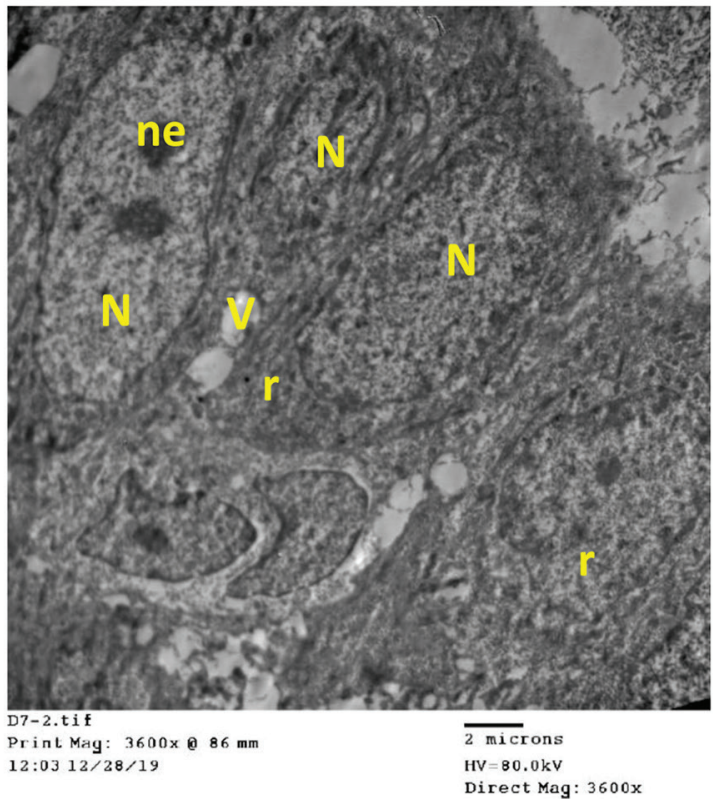

Figure 11: T.E. micrograph of the basal cell layer and the sub-epithelial layer of the wound of subgroup D1A showing elongated basal cells $(B c)$, large vesicular indented nucleus $(N)$ and fibrocytes ( $F c)$, collagen fiber (Co), myelinated nerve fiber (Nv), and macrophage cells (Ma) with electron dens lysosomes (arrow) in the lamina propria; the sub-epithelial area of the wound of subgroup D1B showing electron dens bacterial organism (b), fungal organism (fu), macrophages (Ma), tissue debris (De), and edema (Ed); the epithelial covering in the wound area of subgroup D1C showing elongated basal cells, large vesicular indented nucleus ( $N$ ), one or two prominent nucleoli (ne) and cytoplasm rich in free ribosomes (r), numerous intercellular vacuoles $(V)$, and the surface epithelial cell layers appear flattened having vesicular nucleus

In the present study, rat tongue was the model of choice as it provides adequate tissue sampling and adequate space for intra-oral incisional wound. In addition, the lateral surface of the tongue was chosen as it is non-papillated and is covered with keratinized epithelium and can therefore express most of the epithelial tissues of oral mucosa. Moreover, keratinized epithelium is similar to skin and so we can compare the results with dermal researches [34].

We evaluated wound healing in both diabetic and non-diabetic incisional wounds in a shorter duration interval than in skin wounds [35], [36] because oral 


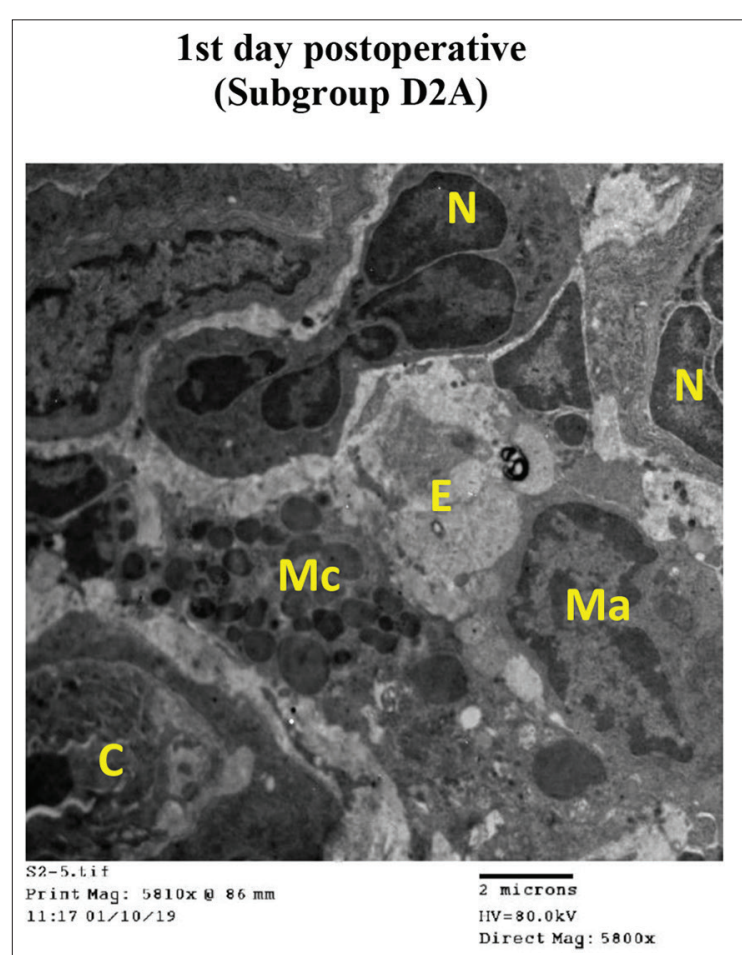

\section{3rd day postoperative \\ (Subgroup D2B)}

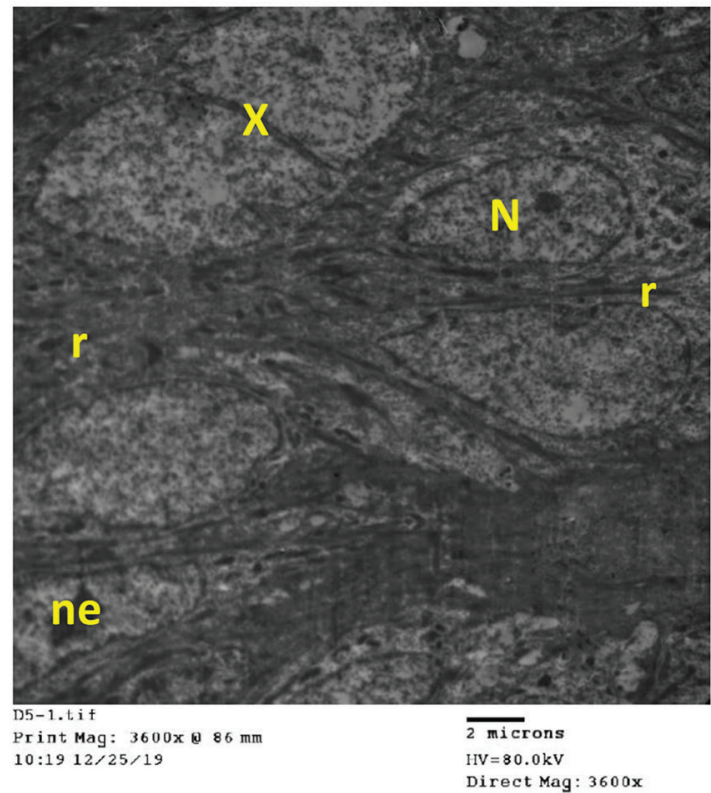

\section{7th day postoperative \\ (Subgroup D2C)}

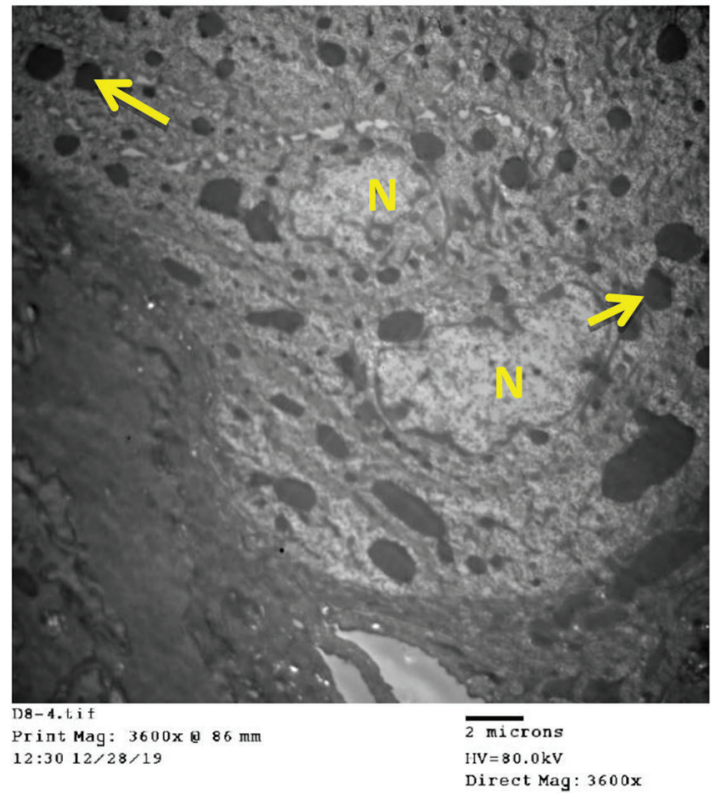

Figure 12: T.E. micrograph of the lamina propria in the regenerating wound area of subgroup D2A showing neutrophil cell with lobulated nucleus $(N)$, macrophage cell $(M a)$, mast cell $(M C)$, edema $(E)$, and blood capillary $(C)$; the regenerated epithelium in the wound area of subgroup D2B showing basal cells with large vesicular indented nucleus ( $N$ ), nucleolus (ne), cytoplasm rich in free ribosomes (r), and some binucleated cells $(X)$; the regenerated epithelium in the wound area of subgroup D2C showing superficial cells with indented nucleus $(N)$ and large amount of variable sized homogenous electron dens hyaline granules (arrow) in cytoplasm

mucosal wound healing generally proceeds faster than in skin [37].

Direct consequences of diabetes that severely affect wound healing process include delay in cell proliferation and decrease in collagen metabolism and all other granulation tissue components [38]. Moreover, it was reported by Abiko and Selimovic [39] that decreased growth factor production might be involved in the impaired wound healing capacity of the oral mucosa in diabetes.

From this point, we postulated that delivering concentrated amounts of growth factors to the wound site using PRP might have a prophylactic and/or therapeutic effect on wound healing in diabetes. In as 


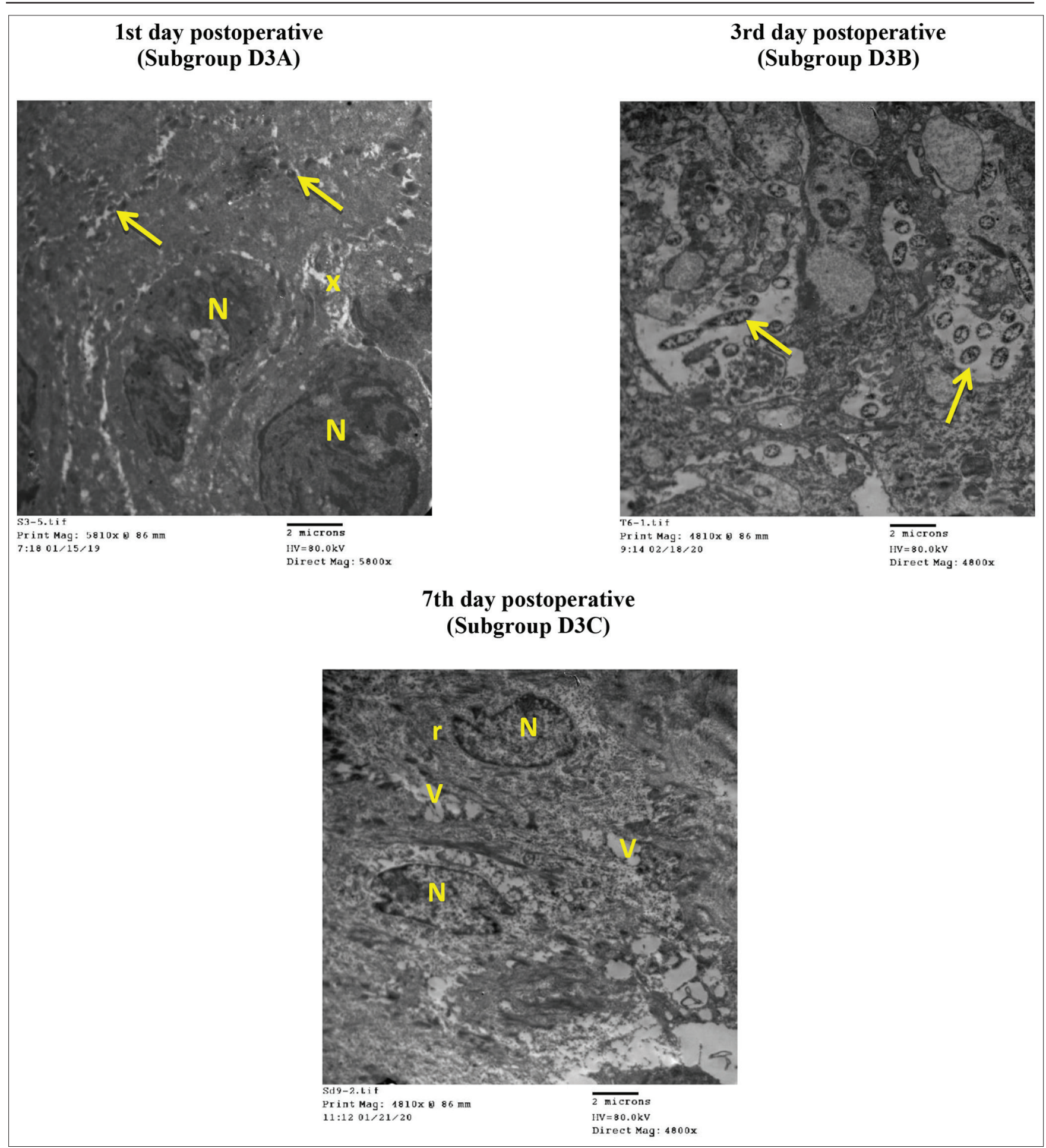

Figure 13: T.E. micrograph of the regenerating epithelium of the wound area of subgroup D3A showing cells with large indented nucleus $(N)$, intercellular junctions (arrow), and wide intercellular spaces (x); the wound area of subgroup D3B showing large amount of macrophage cells with large amount of electron dens particles either tissue debris or bacterial organisms (arrow); the epithelial covering in the healed wound area of subgroup D3C showing elongated basal cells with indented vesicular nucleus $(N)$, cytoplasm rich in free ribosomes $(r)$, and numerous vacuoles $(V)$

much as, it was suggested by Kidman [40] for further researches, that the addition of growth factors and other substances lacking in the diabetic wound might improve wound healing.

In the current study, PRP injection was performed rather than using the gel form because the injection technique is simple, convenient, and provides selective distribution in target regions of the wound, therefore, reduces the required volume of PRP [41].

As the inflammatory phase subsides during the wound healing process, regeneration of the injured tissues begins first in the epithelium and then proceeds in the connective tissue (C.T.) [9].

In our study, we evaluated both epithelium and C.T. during wound healing by various histological 
methods including routine H\&E histological stain and ultrastructural examination by TEM. While, p63 immunohistochemical stain was used to study only the epithelial component; vimentin (VIM) immunohistochemical stain was concerned with the evaluation of the C.T. component of wound healing.

Epithelialization is defined as a process of covering denuded epithelial surface. It is an essential component of wound healing used as a defining parameter of its success. A wound cannot be considered healed in the absence of re-epithelialization [42].

In the control group (subgroup N1), the light microscopic H\&E examination and the ultrastructural TEM examination revealed complete re-epithelialization of the wound area at the $7^{\text {th }}$ day post-operative. Similar results were described in the control group in the study by Rashed et al. [43] but with some variation in the durations because their study was done on buccal mucosal ulcers.

Ultrastructurally, the basal cells of subgroup $\mathrm{N} 1$ in the $1^{\text {st }}$ and $3^{\text {rd }}$ days post-operative showed wideness of the intercellular spaces with presence of desmosomes. This could be explained by Nanci [9] who stated that any damage to the epithelium results in mobilization and migration of epithelial cells at the wound margin. The cells lose their close attachment to each other and to the underlying C.T. within $24 \mathrm{~h}$ of wounding which is viewed histologically as a widening of the intercellular spaces.

Moderate p63 +ve nuclear immune reaction was displayed only in the basal cell layer of the epithelium of subgroup $\mathrm{N} 1$ at all the durations of our experiment, whether in the wound margins or in the healed epithelium. This pattern of p63 expression was consistent with the p63 nuclear localization described by Di Como et al. [44] in normal stratified squamous epithelia.

New C.T. begins to form approximately 2-4 days after wounding, and it is called granulation tissue. Cells and proliferating capillaries are the two major components of granulation tissue. The cells are chiefly fibroblasts and inflammatory cells, including macrophages, lymphocytes, plasma cells, and neutrophils depending on the stage and development of the granulation tissue and the presence of infection [45], [46].

Regarding the C.T. component during wound healing in subgroup N1, H\&E histological examination in addition to VIM immunohistochemical examination displayed the formation of granulation tissue on the $3^{\text {rd }}$ day post-operative. Angiogenesis was obvious in the $3^{\text {rd }}$ and $7^{\text {th }}$ days post-operative. In addition, ultrastructural examination revealed well-developed collagenous C.T. containing collagen bundles, fibrocytes, and blood capillaries in the lamina propria in the $7^{\text {th }}$ day postoperative in subgroup N1.

In accordance to our results, H\&E histological examination in the study by Gazaerly et al. [10] revealed the C.T. with few fibroblasts and endothelial cells with increased amount of collagen in the control group at the 14th day post-wounding in rat tongue. TEM results of the control group in the same study revealed few inflammatory cells, presence of large fibroblasts containing dilated RER, and increased segments of collagen fibers which were arranged in small-unorganized bundles in some areas.

In the present study, it was remarkably noticed that the healing process proceeded very rapidly in subgroup N2 which received PRP before the wound. Complete re-epithelialization of the wound area by lightly stained keratinized stratified squamous epithelium was displayed in the $3^{\text {rd }}$ day post-operative.

In the study carried out by Gazaerly et al. [10] TGF- $\beta 1$, which is one of the growth factors present in $\mathrm{PRP}$, was injected into the dorsal surface of the rat tongue 5 minutes before wounding. H\&E histological examination of the TGF- $\beta 1$ group which is comparable to subgroup N2 in our study showed deeply stained epithelial basal cell layer and almost completed epithelial regeneration earlier than in the control group.

In the $1^{\text {st }}$ day post-operative, TEM examination in the current study displayed elongated basal cells in the wound margin with indented vesicular nucleus, containing nucleolus and their cytoplasm was rich in free ribosomes, in addition to presence of some bi-nucleated cells in subgroup N2. These were all features of active proliferative cells and indicative of protein-synthesizing activity [47].

Immunohistochemical examination revealed moderate p63 +ve nuclear immune reaction in subgroup N2 at the $1^{\text {st }}$ day post-operative in the basal, suprabasal, and spinous cell layers of the epithelium of the wound margins. Meanwhile, p63 +ve nuclear immune reaction was revealed in the basal and suprabasal cell layers of the healed epithelium in the $3^{\text {rd }}$ and $7^{\text {th }}$ days post-operative.

These findings came in line with Farahat et al. [48] who reported that the nuclear expression of p63 immunostaining involved the entire basal, suprabasal, and spinous layers of the epidermis in the PRP-treated group. Meanwhile, they reported that p63 expression involved mainly the basal and suprabasal layers in re-epithelialized epidermis in the control group. Therefore, this was evidence of faster tissue regeneration and epithelialization in the PRP-treated group compared to the control group.

As for the granulation tissue, it appeared in subgroup $\mathrm{N} 2$ in the $1^{\text {st }}$ day post-operative by H\&E histological examination and VIM immunohistochemical examination. It was found to be formed of fibroblasts and inflammatory cells, in addition to newly formed blood vessels. The granulation tissue filling the wound gap exhibited intense VIM +ve nuclear immune reaction of inflammatory cells and fibroblasts.

H\&E histological examination of the TGF$\beta 1$ group in the study by Gazaerly et al. [10] was 
coincidental with our results as it showed remodeling of the C.T. with increased endothelial cell proliferation and congested blood vessels with RBCs.

TEM examination of subgroup $\mathrm{N} 2$ revealed the presence of mononuclear and mast cells in the lamina propria in the $1^{\text {st }}$ day post-operative. Neutrophil cells with lobulated nucleus and lysosomal granules, as well as presence of macrophages, fibroblasts, collagen fibers, and RBCs were observed in the lamina propria in the $3^{\text {rd }}$ day post-operative.

These findings could be attributed to the normal cell response during the inflammatory phase of wound healing which is established within the first 24 hours and can extend for up to two days. The cells that enter the wound during the initial inflammatory stage are platelets and leukocytes, including neutrophils, lymphocytes, mast cells, and macrophages [49], [50]. TEM results of the TGF- $\beta 1$ group in the study by Gazaerly et al. [10] were consistent with our results as they showed mature appearance of the fibroblasts with almost normal RER with many collagen fibers.

Intense VIM +ve immune reaction of fibroblasts and endothelial cells of newly formed blood vessels in the lamina propria was obvious in subgroup N2 in the $1^{\text {st }}$ day post-operative. On the other hand, the immune reaction was moderately +ve for VIM in the $3^{\text {rd }}$ and $7^{\text {th }}$ days postoperative. The newly formed blood vessels were found to be most numerous in the $7^{\text {th }}$ day post-operative.

These findings came in accordance with De Masi et al. [35] who used VIM as an immunohistochemical marker to prove that the use of growth factors accelerated wound healing, stimulated greater angiogenic activity, and accelerated fibroplasia and collagen maturation. Moreover, angiogenesis which was obvious in subgroup N2 could be attributed to the presence of VEGF, PDGF, and FGF in PRP which are potent angiogenesis stimulators [51].

In subgroup N3 which was treated with PRP after the wound, H\&E examination revealed complete re-epithelialization of the wound area at the $7^{\text {th }}$ day postoperative with thick layer of keratinized stratified squamous epithelium. The results of the study by Jee et al. [52] in which PRP was injected in cutaneous wounds in dogs on days 0,2 , and 4 were coincidental with our results but with variation in the durations because the wounds in their study were examined microscopically on day 7,14 , and 21 .

Furthermore, Molina-Miñano et al. [53] studied re-epithelialization and inflammation at 7 and 28 days in skin wounds in rabbits after applying plasma rich in growth factors (PRGF). In the PRGF group, re-epithelialization improved in skin at 7 days, with resolution of the inflammatory process. These observations agreed with our results.

Immunohistochemical evaluation of subgroup N3 displayed intense p63 +ve nuclear immune reaction in the basal and suprabasal cell layers and in some focal areas in the spinous cell layer of the epithelium of the wound margins in the $1^{\text {st }}$ day post-operative. On the other hand, weak p63 +ve nuclear immune reaction in the basal, suprabasal, and spinous cell layers of the epithelium of the wound margin was revealed in the $3^{\text {rd }}$ day post-operative. These observations agreed with Farahat et al. [48] who reported that p63 expression involved entire basal, suprabasal, and spinous layers of the epidermis in the PRP-treated group and, therefore, indicated accelerated wound healing.

By VIM immunohistochemical examination, the epithelium of subgroup N3 was found to be characterized by the presence of some VIM +ve cells scattered in between the -ve VIM keratinocytes in the $3^{\text {rd }}$ and $7^{\text {th }}$ days post-operative. These cells were assumed to be non-keratinocytes most probably melanocytes or inflammatory cells such as lymphocytes because the other non-keratinocytes, including Langerhans cells and Merkel cells were reported to be -ve to VIM immunostaining [54].

The granulation tissue filling the wound gap was apparent in subgroup N3 in the $1^{\text {st }}$ and $3^{\text {rd }}$ days post-operative as revealed by H\&E and VIM immunohistochemical examination. Thus, it was formed earlier than in the control group (subgroup N1). The granulation tissue appeared with inflammatory cell infiltrate and newly formed blood vessels. It exhibited intense VIM +ve nuclear immune reaction of inflammatory cells and fibroblasts.

H\&E histological examination done by Ostvar et al. [55] came in accordance to our results as it revealed increased newly organized collagen bundles and relatively advanced epithelium at the wound junction of PRP-treated wounds as compared to nontreated wounds. Several small vessels (angiogenesis) were also apparent in the PRP treated tissues, whereas only a few vessels were present in control tissues.

Ultrastructurally, the lamina propria in the wound area of subgroup N3 in the $1^{\text {st }}$ day post-operative showed edema, neutrophil, and macrophage cell infiltration, as well as presence of blood vessels. These findings could be attributed to the immediate acute inflammatory reaction which is caused by tissue injury. Neutrophils are the first inflammatory cells to invade the wound and usually appear within few hours of injury. Macrophages enter the wound after 24 hours [9].

VIM immunohistochemical examination of subgroup N3 displayed moderate VIM +ve immune reaction of fibroblasts and endothelial cells of newly formed blood vessels in the lamina propria in the $1^{\text {st }}$ day post-operative. While, the VIM +ve immune reaction was intense in the $3^{\text {rd }}$ day post-operative and moderate in the $7^{\text {th }}$ day post-operative. These findings came in agreement with the study by De Masi et al. [35] where skin wounds injected with growth factors revealed VIM +ve immune reaction of fibroblasts and blood vessels.

Most of our results regarding subgroup N3 were in good agreement with Duymus et al. [36] who 
compared the effects of three different forms of PRP on the recovery of open dermal wounds in rats. In their study, PRP was applied to the wounds on postoperative days $1,4,7$, and 10 same as our study. They reported that all PRP preparations had significant positive effects on wound healing when compared with the control group. The mean histopathological scores of epithelialization, inflammation, and fibrosis were significantly better in all PRP groups than the scores in the control group.

Collectively, all the mentioned results in the non-diabetic group in the present study revealed overall enhanced wound healing in subgroup N3 over the control (subgroup N1) although the epithelialization rate was similar in both subgroups. On the other hand, subgroup N2 demonstrated the highest epithelialization rate and the fastest wound healing rate.

Regarding the diabetic group in the current study, H\&E and TEM examination revealed delayed wound healing in subgroup D1 which did not receive any PRP treatment. By the $7^{\text {th }}$ day post-operative, partial healing with lightly stained keratinized stratified squamous epithelium was noticed with presence of small wound gap.

This delay in the rate of healing in diabetic rats as compared with normal control rats came in agreement with $\mathrm{Yu}$ et al. [56]. Furthermore, Velander et al. [57] reported significant delayed wound healing in diabetic pigs as full re-epithelialization occurred $50 \%$ later in the diabetic than in the non-diabetic pigs. These authors assumed that the impaired wound healing in diabetes was due to decreased concentration of growth factors in the wound fluid especially IGF- 1 and TGF- $\beta$.

The presence of vacuoles in subgroup D1 revealed by TEM examination in the current study could be attributed to possible bacterial infection. Cytoplasmic vacuolization is a well-known morphological phenomenon observed in mammalian cells after exposure to bacterial or viral pathogens. Bacterial protein toxins can serve as vacuolization inducers. Vacuolization in cells is considered as an adaptive physiological response, presumably for damage limitation [58], [59].

By H\&E and MT histological examination, thick granulation tissue was clearly noticed filling the wound gap and containing inflammatory cell infiltrate on the $3^{\text {rd }}$ day post-operative in subgroup D1. However, by immunohistochemical examination, the granulation tissue appeared with intense VIM +ve nuclear immune reaction of inflammatory cells and fibroblasts in both the $1^{\text {st }}$ and $3^{\text {rd }}$ days post-operative.

The lamina propria of subgroup D1, under TEM, appeared to be formed of fibrocytes, collagen fibers, myelinated nerve fibers, and macrophage cells containing electron dens lysosomes in the $1^{\text {st }}$ day post-operative. While in the $3^{\text {rd }}$ day post-operative, the lamina propria displayed the presence of electron dens bacterial organisms, fungal organisms, macrophages, tissue debris, and edema.

These findings assured the presence of infection in the wound in subgroup D1. This could be explained by Leoni et al. [60] who stated that the mucosal epithelium is at the interface of the external environment containing bacteria and antigens, and internal tissue compartments. Thus, repair of the mucosal surface does not occur in a sterile environment.

Diabetes was reported to increase the susceptibility to oral infection [39]. Furthermore, diabetes was declared to cause impaired production of cytokines and their receptors that interfere with the function of cells such as macrophages and neutrophils which could in turn impair their defensive function against bacteria [61]

TEM results of the diabetic group in the study by Gazaerly et al. [10] supported our findings as it showed abnormal granulation tissue with increased numbers of lymphatics and blood vessels and the fibroblasts were inactive with notched nucleus, dilated RER, and moderate collagen fibrils.

Rapid wound healing was obvious in the present study in the diabetic subgroup D2 which was treated with PRP before the wound, when compared with subgroup D1. Complete re-epithelialization with thick edematous layer of keratinized stratified squamous epithelium was revealed in subgroup D2 in the $3^{\text {rd }}$ day post-operative.

Ultrastructurally, the lamina propria in subgroup $\mathrm{D} 2$ in the $1^{\text {st }}$ day post-operative was found to contain macrophages, neutrophils with lobulated nucleus, mast cells, collagen fibers, edema, blood capillaries, and myelinated nerve fibers.

Interestingly, these observations proved the absence of bacterial infection in subgroup D2 in contrast to the case in subgroup D1 which could be attributed to the antimicrobial action of PRP [62], [63]. Moreover, the presence of neutrophils and macrophages could be attributed to their defensive role in wound healing. Neutrophils cleanse debris and bacteria to provide a good environment for wound healing and macrophages facilitate phagocytosis of bacteria and damaged tissue [61].

In agreement with our postulations, Gazaerly et al. [10] by TEM examination of the diabetic + TGF- $\beta 1$ group reported that wounds were found to be almost similar to the non-diabetic control group. Fibroblasts had abundant RER and were surrounded by an expressive amount of thin and well-organized collagen fibrils. Some superficial epithelial cells showed double nuclei which is an indication of cell division.

VIM immunohistochemical evaluation of subgroup D2 revealed intense VIM +ve immune reaction of fibroblasts and endothelial cells of newly formed blood vessels in the lamina propria in all the durations of the experiment. Moreover, in the $3^{\text {rd }}$ day 
and $7^{\text {th }}$ days post-operative intense VIM +ve nuclear immune reaction of inflammatory cells and fibroblasts present in the granulation tissue was exhibited.

The quantity of capillaries and fibroblasts determine the duration of wound healing. The presence of a large quantity of granulation tissue and abundant capillaries is an indication of accelerated wound healing [56].

As for the diabetic subgroup D3 which received $\mathrm{PRP}$ treatment after the wound, complete re-epithelialization by thin, lightly stained keratinized stratified squamous epithelium with regular rete pegs was observed in the $7^{\text {th }}$ day post-operative.

Our H\&E histological results came in one line with Farahat et al. [48] who evaluated the effect of PRP on chronic wound healing in 20 patients with chronic wounds of different causes including diabetic ulcers. Partial re-epithelialization of the epidermis in the control group with a region of angiogenesis compared to complete re-epithelialization of the epidermis was revealed on the $7^{\text {th }}$ day in the PRPtreated group.

H\&E histological stain and VIM immunohistochemical examination displayed granulation tissue in the $3^{\text {rd }}$ day post-operative in subgroup D3. The granulation tissue occupying the wound gap was found to exhibit intense VIM +ve nuclear immune reaction of inflammatory cells and fibroblasts.

Large amount of macrophage cells containing large amount of electron dens particles either tissue debris or bacterial organisms were observed in subgroup D3 in the $3^{\text {rd }}$ day post-operative under TEM examination. These findings could be explained by the fact that platelets in PRP produce signaling proteins that attract macrophages and so play a role in host defense mechanism at the wound site [60], [64]. Accordingly, authors in the current study assumed that PRP protected the diabetic wound from further bacterial infection in subgroup D3. This postulation was confirmed by Marx [65] who stated that PRP could inhibit bacterial growth.

In accordance with our results, Venter et al. [5] demonstrated that PRP-treated diabetic wounds showed faster wound closure. The neo-epidermis was thick and granulation tissue was more developed in PRP-treated rats than in control rats.

Taken together, all the observations of the present study revealed the most accelerated wound healing in the subgroups treated with PRP before the wound, whether non-diabetic or diabetic, which occurred very early at the $3^{\text {rd }}$ day post-operative in both cases. While complete wound healing was revealed at the $7^{\text {th }}$ day post-operative in both the non-diabetic and diabetic subgroups treated with PRP after the wound, which was like the non-diabetic control subgroup. While, the diabetic non-treated subgroup only showed partial wound healing at the $7^{\text {th }}$ day post-operative.

\section{Conclusion}

It was concluded that a single injection of PRP could be used as a prophylactic to prevent expected impaired wound healing in diabetic oral mucosal wounds and to enhance wound healing in non-diabetic wounds. It was also concluded that PRP could be used as a therapeutic to accelerate wound healing in diabetic oral mucosal wounds as it could raise the rate of healing to a level like normal wound healing. In addition, PRP could be used as a therapeutic to enhance wound healing in non-diabetic wounds.

\section{References}

1. Abd-Elmotelb MA. Morphometric, histological and immunohistochemical study of tongue epithelium in diabetic rats. Life Sci J. 2018;15:1-6.

2. Rabo A, Mohamed RA. Comparative study of the effect of Allium sativum (Garlic), Allium cepa (Onion) and insulin on the lingual papillae of streptozotocin induced diabetic albino rats. In: Oral Biology. Egypt: Ain Shams University, Faculty of Dentistry 2018. p. 150. https://doi.org/10.21608/ejh.2020.26939.1267

3. Tesseromatis C, Kotsiou A, Parara H, Vairaktaris E, Tsamouri M. Morphological changes of gingiva in streptozotocin diabetic rats. Int J Dent. 2009;2009:725628. https://doi. org/10.1155/2009/725628

PMid:20339569

4. Umasankar K, Balwin N, Backyavathy DM. Wound healing activity of topical mentha piperita and cymbopogan citratus essential oil on streptozotocin induced rats. Asian J Pharm Clin Res. 2013;6:180-3

5. Venter NG, Marques RG, Dos Santos JS, Monte-Alto-Costa A. Use of platelet-rich plasma in deep second and third-degree burns. Burns. 2016;42:807-14. https://doi.org/10.1016/j. burns.2016.01.002

PMid:26822695

6. Graves DT, Liu R, Oates TW. Diabetes-enhanced inflammation and apoptosis impact on periodontal pathosis. Periodontol 2000. 2007;45(1):128-37. https://doi. org/10.1111/j.1600-0757.2007.00219.x

PMid:17850453

7. Berdal M, Appelbom HI, Eikrem JH, Lund A, Zykova S, Busund LT, et al. Aminated $\beta$-1,3-d-glucan improves wound healing in diabetic db/db mice. Wound Repair Regen. 2007;15(6):825-32. https://doi.org/10.1111/j.1524-475x.2007.00286.x

PMid:18028130

8. Thorne $\mathrm{CH}$, Bartlett SP, Beasley RW, Aston SJ, Gurtner GC, Spear SL. Wound healing: Normal and abnormal. In: Grabb and Smith's Plastic Surgery. Alphen aan den Rijn: Wolters Kluwer Health Adis (ESP); 2013.

9. Nanci A. Repair and regeneration of oral tissues. In: Ten Cate's Oral Histology: Development, Structure, and Function. St. Louis, 
Missouri: Elsevier; 2018. p. 729-740.

10. Gazaerly HE, Elbardisey DM, Eltokhy HM, Teaama D. Effect of transforming growth factor beta 1 on wound healing in induced diabetic rats. Int J Health Sci. 2013;7(2):160-72. https://doi. org/10.12816/0006040

PMid:24421745

11. Setta HS, Elshahat A, Elsherbiny K, Massoud K, Safe I. Platelet-rich plasma versus platelet-poor plasma in the management of chronic diabetic foot ulcers: A comparative study. Int Wound J. 2011;8(3):307-12. https://doi. org/10.1111/j.1742-481x.2011.00797.x

PMid:21470370

12. Marx RE. Platelet-rich plasma (PRP): What is PRP and what is not PRP? Implant Dent. 2001;10(4):225-8. https://doi. org/10.1097/00008505-200110000-00002

PMid:11813662

13. Kramer ME, Keaney TC. Systematic review of platelet-rich plasma (PRP) preparation and composition for the treatment of androgenetic alopecia. J Cosmet Dermatol. 2018;17(5):666-71. https://doi.org/10.1111/jocd.12679

PMid:29790267

14. Tian J, Cheng LH, Cui X, Lei XX, Tang JB, Cheng B. Application of standardized platelet-rich plasma in elderly patients with complex wounds. Wound Repair Regen. 2019;27(3):268-76. https://doi.org/10.1111/wrr.12702 PMid:30693614

15. Dhillon RS, Schwarz EM, Maloney MD. Platelet-rich plasma therapy future or trend? Arthritis Res Ther. 2012;14(4):219. https://doi.org/10.1186/ar3914

PMid:22894643

16. Textor J. Platelet-rich plasma (PRP) as a therapeutic agent: Platelet biology, growth factors and a review of the literature. In: Lana JF, Santana MH, Belangero WD, Luzo AC, editors. Platelet-Rich Plasma Regenerative Medicine: Sports Medicine, Orthopedic, and Recovery of Musculoskeletal Injuries. Berlin, Germany: Springer Science and Business Media; 2014. p. 61-94. https://doi.org/10.1007/978-3-642-40117-6_2

17. Davydova L, Tkach G, Tymoshenko A, Moskalenko A, Sikora V, Kyptenko L, et al. Anatomical and morphological aspects of papillae, epithelium, muscles, and glands of rats' tongue: Light, scanning, and transmission electron microscopic study. Int Med Appl Sci. 2017;9(3):168-77. https://doi. org/10.1556/1646.9.2017.21

PMid:29201443

18. Goździewska-Harłajczuk K, Klećkowska-Nawrot J, Barszcz K, Marycz K, Nawara T, Modlińska K, et al. Biological aspects of the tongue morphology of wild-captive WWCPS rats: A histological, histochemical and ultrastructural study. Anat Sci Int. 2018;93(4):514-32. https://doi.org/10.1007/s12565-018-0445-y PMid:29948977

19. Noszczyk B, Majewski S. p63 Expression during normal cutaneous wound healing in humans. Plast Reconstr Surg 2001;108:1242-7; discussion 1248. https://doi. org/10.1097/00006534-200110000-00023

PMid:11604626

20. Fuyuhiro Y, Yashiro M, Noda S, Kashiwagi S, Matsuoka J, Doi Y, et al. Clinical significance of vimentin-positive gastric cancer cells. Anticancer Res 2010;30(12):5239-43.

PMid:21187520

21. Robinson-Bennett B, Han A. Handbook of Immunohistochemistry and in situ Hybridization of Human Carcinomas. Amsterdam, Netherlands: Elsevier Science; 2006.

22. Choudhary P, Choudhary OP. Uses of transmission electron microscope in microscopy and its advantages and disadvantages. Int J Curr Microbiol Appl Sci. 2018;7(5):743-7. https://doi.org/10.20546/ijcmas.2018.705.090

23. Williams DB, Carter CB. The transmission electron microscope. In: McNamara A, editor. Transmission Electron Microscopy a Textbook for Materials Science. United States: Springer; 2009. p. 3-22. https://doi.org/10.1007/978-0-387-76501-3_1

24. Middleton KK, Barro V, Muller B, Terada S, Fu FH. Evaluation of the effects of platelet-rich plasma (PRP) therapy involved in the healing of sports-related soft tissue injuries. lowa Orthop J. 2012;32:150-63.

PMid:23576936

25. Tandon PN, Mahajan RC, Anand N, Basu SK, Ganguly NK, Kamboj VP, et al. Guidelines for Care and Use of Animals in Scientific Research. New Delhi: Indian National Science Academy; 2000.

26. Bhattacharya S, Aggarwal R, Singh VP, Ramachandran $S$, Datta M. Downregulation of miRNAs during delayed wound healing in diabetes: Role of dicer. Mol Med. 2015;21:847-60. https://doi.org/10.2119/molmed.2014.00186 PMid:26602065

27. Ebaid H, Ahmed OM, Mahmoud AM, Ahmed RR. Limiting prolonged inflammation during proliferation and remodeling phases of wound healing in streptozotocin-induced diabetic rats supplemented with camel undenatured whey protein. BMC Immunol. 2013;14:31. https://doi.org/10.1186/1471-2172-14-31 PMid:23883360

28. Dhurat R, Sukesh MS. Principles and methods of preparation of platelet-rich plasma: A review and author's perspective. J Cutan Aesthet Surg. 2014;7:189-97. https://doi. org/10.4103/0974-2077.150734 PMid:25722595

29. Elsaadany B, El Kholy S, El Rouby D, Rashed L, Shouman T. Effect of transplantation of bone marrow derived mesenchymal stem cells and platelets rich plasma on experimental model of radiation induced oral mucosal injury in albino rats. Int J Dent. 2017;2017:8634540. https://doi.org/10.1155/2017/8634540 PMid:28337218

30. Drury RA, Wallington EA. Carleton's Histological Techniques. $5^{\text {th }}$ ed. New York: Oxford University Press; 1980. p. 195. https://doi. org/10.1038/modpathol.2011.89

31. Martin SE, Temm CJ, Goheen MP, Ulbright TM, Hattab EM Cytoplasmic p63 immunohistochemistry is a useful marker for muscle differentiation: An immunohistochemical and immunoelectron microscopic study. Mod Pathol. 2011;24:1320-6. PMid:21623385

32. Kurihara $\mathrm{K}$, Isobe $\mathrm{T}$, Yamamoto $\mathrm{G}$, Tanaka $\mathrm{Y}$, Katakura $\mathrm{A}$, Tachikawa T. Expression of BMI1 and ZEB1 in epithelialmesenchymal transition of tongue squamous cell carcinoma. Oncol Rep. 2015;34(2):771-8. https://doi.org/10.3892/or.2015.4032 PMid:26043676

33. Bozzola JJ, Russell LD. Electron Microscopy: Principles and Techniques for Biologists. $2^{\text {nd }}$ ed. Boston: Jones and Bartlett Publishers International; 1999.

34. Sciubba JJ, Waterhouse JP, Meyer J. A fine structural comparison of the healing of incisional wounds of mucosa and skin. J Oral Pathol Med 1978;7(4):214-27. https://doi. org/10.1111/j.1600-0714.1978.tb01596.x

PMid:99502

35. De Masi EC, Campos AC, De Masi FD, Ratti MA, Ike IS, De Masi RD. The influence of growth factors on skin wound healing in rats. Braz J Otorhinolaryngol. 2016;82(5):512-21. https://doi. org/10.1016/j.bjorl.2015.09.011 PMid:26832633

36. Duymus ME, et al. Comparison of the effects of platelet rich plasma prepared in various forms on the healing of dermal wounds in rats. Wounds. 2016;28(3):99-108.

37. Wong JW, Gallant-Behm C, Wiebe C, MakK, HartDA, Larjava H, et 
al. Wound healing in oral mucosa results in reduced scar formation as compared with skin: Evidence from the red Duroc pig model and humans. Wound Repair Regeneration. 2009;17(5):717-29. https://doi.org/10.1111/j.1524-475x.2009.00531.x PMid:19769724

38. Galkowska H, Wojewodzka U, Olszewski WL. Chemokines, cytokines, and growth factors in keratinocytes and dermal endothelial cells in the margin of chronic diabetic foot ulcers. Wound Repair Regen. 2006;14(5):558-65. https://doi. org/10.1111/j.1743-6109.2006.00155.x

39. Abiko $Y$, Selimovic D. The mechanism of protracted wound healing on oral mucosa in diabetes. Review. Bos J Basic Med Sci. 2010;10(3):188-91. https://doi.org/10.17305/bjbms.2010.2683

40. Kidman K. Tissue repair and regeneration: The effects of diabetes on wound healing. Diabetic Foot J. 2008;11(2):73-80.

41. Dionyssiou D, Demiri E, Foroglou P, Cheva A, Saratzis N, Aivazidis $\mathrm{C}$, et al. The effectiveness of intralesional injection of platelet-rich plasma in accelerating the healing of chronic ulcers: An experimental and clinical study. Int Wound J. 2013;10(4):397406. https://doi.org/10.1111/j.1742-481x.2012.00996. PMid:22672105

42. Pastar I, Stojadinovic O, Yin NC, Ramirez H, Nusbaum AG, Sawaya A, et al. Epithelialization in wound healing: A comprehensive review. Adv Wound Care. 2014;3(7):445-64. PMid:25032064

43. Rashed FM, GabAllah OM, AbuAli SY, Shredah MT. The effect of using bone marrow mesenchymal stem cells versus platelet rich plasma on the healing of induced oral ulcer in albino rats. Int $\mathrm{J}$ Stem Cells. 2019;12(1):95-106. https://doi.org/10.15283/ijsc18074 PMid:30836730

44. Di Como CJ, Urist MJ, Babayan I, Drobnjak M, Hedvat CV, Teruya-Feldstein $\mathrm{J}$, et al. p63 expression profiles in human normal and tumor tissues. Clin Cancer Res. 2002;8(2):494-501. PMid:11839669

45. Häkkinen L, Larjava $H$, Koivisto L. Granulation tissue formation and remodeling. Endod Top. 2012;24(1):94-129. https://doi. org/10.1111/etp.12008

46. Gurtner GC, Werner S, Barrandon Y, Longaker MT. Wound repair and regeneration. Nature. 2008;453(7193):314-21. https://doi.org/10.1038/nature07039

47. Kumar GS. Oral mucous membrane. In: Orban's Oral Histology and Embryology. India: Elsevier; 2015. p. 194-240.

48. Farahat A, Salah HE, Al-Shraim M. Evaluation of the clinical and histopathological effect of Platelet rich plasma on chronic wound healing. Int Res J Basic Clin Stud. 2014;2(6):55-61.

49. GonzalezAC, CostaTF, deAraújoAndradeZ, MedradoAR. Wound healing a literature review. Anais Bras Dermatol. 2016;91:61420. https://doi.org/10.1590/abd1806-4841.20164741 PMid:27828635

50. Eming SA, Krieg T, Davidson JM. Inflammation in wound repair: Molecular and cellular mechanisms. J Investig Dermatol. 2007;127(3):514-25. https://doi.org/10.1038/sj.jid.5700701 PMid:17299434

51. Italiano JE Jr., Richardson JL, Patel-Hett S, Battinelli E, Zaslavsky A, Short S, et al. Angiogenesis is regulated by a novel mechanism: Pro and antiangiogenic proteins are organized into separate platelet alpha granules and differentially released. Blood. 2008;111(3):1227-33. https://doi.org/10.1182/ blood-2007-09-113837

52. Jee $\mathrm{CH}$, Eom NY, Jang HM, Jung HW, Choi ES, Won JH, et al. Effect of autologous platelet-rich plasma application on cutaneous wound healing in dogs. J Vet Sci. 2016;17(1):79-87.

53. Molina-Miñano $F$, López-Jornet $P$, Camacho-Alonso F, VicenteOrtega $\mathrm{V}$, et al. The use of plasma rich in growth factors on wound healing in the skin: Experimental study in rabbits. Int Wound $\mathrm{J}$. 2009;6(2):145-8. https://doi.org/10.1111/j.1742-481x.2009.00592.x PMid:19432664

54. Marchetti C, Farina A, Cornaglia Al. Microscopic, immunocytochemical, and ultrastructural properties of periimplant mucosa in humans. J Periodontol. 2002;73:555-63. https://doi.org/10.1902/jop.2002.73.5.555 PMid: 12027260

55. Ostvar O, Shadvar S, Yahaghi E, Azma K, Fayyaz AF, Ahmadi K, et al. Effect of platelet-rich plasma on the healing of cutaneous defects exposed to acute to chronic wounds: A clinicohistopathologic study in rabbits. Diagn Pathol. 2015;10(85):1-6. https://doi.org/10.1186/s13000-015-0327-8 PMid:27802803

56. Yu H, Yuan L, Xu M, Zhang Z, Duan H. Sphingosine kinase 1 improves cutaneous wound healing in diabetic rats. Injury. 2014;45:1054-8.

57. Velander P, Theopold C, Hirsch T, Bleiziffer O, Zuhaili B, Fossum $\mathrm{M}$, et al. Impaired wound healing in an acute diabetic pig model and the effects of local hyperglycemia. Wound Repair Regen. 2008;16(2):288-93. https://doi. org/10.1111/j.1524-475x.2008.00367.x

PMid: 18318812

58. Shubin AV, Demidyuk IV, Komissarov AA, Rafieva LM, Kostrov SV Cytoplasmic vacuolization in cell death and survival. Oncotarget. 2016;7(34):55863-89. https://doi.org/10.18632/oncotarget.10150 PMid:27331412

59. Henics T, Wheatley DN. Cytoplasmic vacuolation, adaptation and cell death: A view on new perspectives and features. Biol Cell. 1999;91(7):485-98. https://doi.org/10.1016/ s0248-4900(00)88205-2

PMid: 10572624

60. Leoni G, Neumann PA, Sumagin R, Denning TL, Nusrat A. Wound repair: Role of immune-epithelial interactions. Mucosal Immunol. 2015;8(5):959-68.

PMid:26174765

61. Qing C. The molecular biology in wound healing and nonhealing wound. Chin J Traumatol. 2017;20(4):189-93. https:// doi.org/10.1016/j.cjtee.2017.06.001

PMid:28712679

62. Li H, Hamza T, Tidwell JE, Clovis N, Li B. Unique antimicrobial effects of platelet-rich plasma and its efficacy as a prophylaxis to prevent implant-associated spinal infection. Adv Healthc Mater. 2013;2(9):1277-84. https://doi.org/10.1002/adhm.201200465 PMid:23447088

63. El Backly R, Ulivi V, Tonachini L, Cancedda R, Descalzi F, Mastrogiacomo M. Platelet lysate induces in vitro wound healing of human keratinocytes associated with a strong proinflammatory response. Tissue Eng Part A. 2011;17:1787800. https://doi.org/10.1089/ten.tea.2010.0729 PMid:21385008

64. Koh TJ, DiPietro LA. Inflammation and wound healing: The role of the macrophage. Exp Rev Mol Med. 2011;13:e23-3. PMid:21740602

65. Marx RE. Platelet-rich plasma: Evidence to support its use. J Oral Maxillofac Surg. 2004;62(4):489-96. https://doi.org/10.1016/j. joms.2003.12.003

PMid:15085519 